\title{
A double-cylinder model incorporating confinement effects for the analysis of corrosion- caused cover cracking in reinforced concrete structures
}

\author{
Ray Kai Leung Su, Yanlong Zhang* \\ Department of Civil Engineering, The University of Hong Kong, Pokfulam Road, Hong Kong, PRC
}

\begin{abstract}
In this paper, a double-cylinder model with a consideration of concrete confinement effects is proposed to simulate reinforcement corrosion-caused cover cracking. The analytical model incorporates force equilibrium in both tangential and radial directions as well as volume expansion and deformation compatibility in the steel-rust-concrete interface. Confinement effects outside the cylinders are taken into account by comparing the numerical and available experimental results. Parametric studies are conducted to investigate the variations of the critical volume of consumed steel, critical expansive pressure and time to cover cracking.
\end{abstract}

Keywords: A. Steel reinforced concrete
B. Modelling studies
C. Rust
C. Corrosion cracking

\section{Introduction}

The corrosion of reinforcing bars in concrete has been identified as one of the major worldwide deterioration mechanisms for reinforced concrete (RC) structures $[1,2]$, which can significantly affect the serviceability, durability and strength of such RC structures [2].

\footnotetext{
* Corresponding author. Tel.:+852 68456260

E-mail address: ylzhang200@gmail.com (Y. Zhang)
} 
Damage to concrete due to corrosion-caused expansive pressure can lead to cracking and even spalling of the surrounding concrete. It is imperative, therefore, to understand the mechanism of corrosion-induced cover cracking and to provide a theoretical model for the structural integrity and lifetime analysis of RC structures. Moreover, in order to make appropriate decisions regarding the structural inspection, strengthening, repair, replacement and demolition of old RC structures, knowledge of the amount of reinforcing steel lost, the corrosion-caused expansive pressure and the remaining lifetime of such RC structures is essential.

In recent decades, various analytical models [1-24] have been developed to simulate the corrosion of RC structures. Bažant [5] proposed a uniform-cylinder analytical model with a homogeneous linear elastic material to simulate reinforcement corrosion-induced cover cracking. The model was modified by Liu and Weyers [1] to account for a porous zone around the steel-concrete interface in which the corrosion products needed to be filled prior to the development of expansive pressure to the concrete cover. Based on this model, EI Maaddawy and Soudki [6] predicted the time from corrosion initiation to concrete cracking. Papakonstantinou and Shinozuka [3] further extended EI Maaddawy and Soudki's model [6] to simulate all stages of RC corrosion, including corrosion initiation, crack initiation and propagation.

Tepfers [7] proposed a double-cylinder model in which the cylinder was divided into uncracked and cracked parts. Many researchers attempted to improve this model by taking into account the residual tensile strength in the cracked concrete. Wang and Liu [8-9] assumed that the concrete in the cracked cylinder was an isotropic linear elastic material with 
an elastic modulus equal to that of the outer cylinder. Based on this model, Han et al. [4] examined the process of the degradation of flexural strength in RC concrete members caused by steel corrosion. Bhargava et al. [2, 10-12] postulated that the concrete in the cracked cylinder was an isotropic linear elastic material with a reduced elastic modulus compared to that of the outer uncracked concrete cylinder. Balafas and Burgoyne [13] proposed a doublecylinder model based on the fracture mechanics theory to determine structural lifetime from corrosion initiation to cover spalling. Li et al. [14-15] assumed that the cracked concrete cylinder was an isotropic material with a reduced elastic modulus in the tangential direction. However, the stress continuity and strain compatibility conditions on the common boundary between the uncracked and cracked concrete cylinders were not satisfied in their model. Chernin et al. [16] extended the double-cylinder model by adopting a consistent stress-strain relationship for both uncracked and cracked concrete cylinders and ensured the continuity of stress and strain on the common boundary between the two cylinders. Kim et al. [17] developed a model to explore realistic mechanical properties of the corrosion layer, including the pressure-free corrosion strain and the stiffness of the corrosion layer, with the consideration of corrosion products penetrating into the concrete pores and cracks around a steel bar. Zhao et al. [18] derived a model using elastic mechanics to analyze uncracked concrete and damage mechanics with a gradually changing elastic modulus to simulate cracked concrete. Moreover, the effects of the corrosion products penetrating into concrete pores and cracks and the displacement in the rust-concrete surface were duly considered in their model. Shodja et al. [19-20] developed a nonlinear model in which the steel, rust and concrete were assumed, respectively, to be linear isotropic, power-law and nonlinear 
anisotropic materials. Using this model, the volume ratio of the corrosion products inside the cracks to the volume of the cracks was determined.

In practice, reinforcing bars are usually placed near the concrete surface after providing codified nominal concrete cover to maximize the sectional moment capacity. For all the thick-walled cylinder models available in the literature [1-24], the size of the uncracked cylinder is equal to the distance measured from the center of the reinforcing bar to the nearest concrete surface that is the thinnest cover surface. All predicted results based on the thickwalled cylinder models, such as the time to cracking, the corrosion-caused expansive pressure, the width of crack and the amount of consumed iron, are obtained by solely analyzing the concrete cylinders without considering the effects of confinement pressure provided by the concrete outside the cylinders; this can, however, restrain the expansion of concrete cylinders, reduce the tensile strains developed in the cylinders, and hence slow down the cracking process of the cover. Without considering this beneficial confinement effect outside the cylinder, the predicted life of cover would be underestimated.

In this study, a double-cylinder model is developed with the consideration of the aforementioned confinement effect together with other, unique, features including: (1) accounting for the residual tensile stress in cracked concrete, (2) considering the stiffness contribution from both reinforcement and corrosion products, (3) modeling the volume compatibility condition in the steel-rust-concrete interface, and (4) simulation of the continuity of stress and strain on the common boundary between the uncracked and cracked concrete cylinders. This model is capable of predicting the time to cracking, the corrosioncaused expansive pressure and the amount of iron consumed during the corrosion-caused 
cracking process. A numerical parametric study has been carried out to investigate the effects of the ratio of cover thickness to reinforcing bar diameter, tensile strength of concrete, mechanical behavior and chemical composition of rust, and the volume of corrosion products diffused into the cracks on the critical volume of consumed steel, critical expansive pressure and time to cover cracking caused by corrosion.

\section{The analytical model}

The reinforcement corrosion problem considered in this study is illustrated in Fig. 1a. When the reinforcing bar is placed below the mid-depth of the concrete section, $c_{\mathrm{b}}$ and $c_{\mathrm{t}}$ are the thicknesses of the thinner (bottom) and thicker (top) covers, respectively. In the figure, $P_{\text {rust }}$ is the expansive pressure caused by the deformation of the corrosion products, $d_{0}$ is the thickness of the porous zone, $D$ is the initial diameter of the reinforcing bar embedded in the concrete, $r_{0}$ is the crack front and $t_{\mathrm{c}, \mathrm{e}}$ is the time to cover cracking for the actual case. The first analytical model, as shown in Fig. 1b, is the traditional model widely found in the literature in which the radius of the concrete cylinder is solely determined from the thickness of the thinner cover and is equal to $D / 2+d_{0}+c_{\mathrm{b}, 0}$, where $c_{\mathrm{b}, 0}=c_{\mathrm{b}} . P_{\mathrm{c}, 0}$ is the confining pressures provided by the uncracked concrete cylinder and $\sigma_{\theta, 0}(r)$ is the residual tensile stresses provided by the cracked concrete cylinder. The life of concrete cover predicted by this model is likely to be underestimated as the confinement pressure outside the cylinder is ignored.

To yield a more accurate prediction, the second model, as depicted in Fig. 1c, with a cylinder radius equal to $D / 2+d_{0}+c_{\mathrm{b}, 1}\left(c_{\mathrm{b}, 1} \geq c_{\mathrm{b}, 0}\right)$, which is larger than or equal to that of the first model, is proposed. By comparing the time to cover cracking obtained from this model to the 
available experimental results, the required size of the cylinder can be calibrated (details to be described in Section 4.1). The predicted results from this model, which used an enlarged concrete cylinder to account for the concrete confinement effects, are believed to better simulate real behavior. By comparing the predicted results (including cover thickness, volume of rust, corrosion-caused expansive pressure and time to cover cracking) obtained from the second model with those from the first model, a set of confinement adjustment factors ( $\psi_{c}, \psi_{v}, \psi_{p}$ and $\psi_{t}$ all greater than or equal to 1) defined in Eqs. (1a) to (1d) can be obtained. Using this set of factors, the results of the parametric study (to be presented in Section 4.2) for the first model with a constant thickness of concrete covers $\left(c_{\mathrm{b}}=c_{\mathrm{t}}\right)$ can be extended to more realistic results for sections with unequal thicknesses of concrete covers.

$$
\begin{array}{cc}
c_{\mathrm{b}, 1}=\psi_{c} c_{\mathrm{b}, 0} & 1 \leq \psi_{c} \\
V_{\mathrm{rust}, 1}=\psi_{v} V_{\mathrm{rust}, 0} & 1 \leq \psi_{v} \\
P_{\text {rust }, 1}=\psi_{p} P_{\text {rust }, 0} & 1 \leq \psi_{p} \\
t_{\mathrm{c}, 1}=\psi_{t} t_{\mathrm{c}, 0} & 1 \leq \psi_{t}
\end{array}
$$

where $c_{\mathrm{b}, 1}, V_{\text {rust,1, }}, P_{\text {rust,1 }}$ and $t_{\mathrm{c}, 1}$ are, respectively, cover thickness, volume of rust, corrosioncaused expansive pressure and time to cover cracking of the second model, whereas $c_{\mathrm{b}, 1}$, $V_{\text {rust }, 0}, P_{\text {rust }, 0}$ and $t_{\mathrm{c}, 0}$ are, respectively, cover thickness, volume of rust, corrosion-caused expansive pressure and time to cover cracking of the first model.

\section{Analytical solution of the model}

In the present study, the analytical solution of the generalized model representing the first model when $i=0$ and the second model when $i=1$ will be developed. The analytical solution 
for a generalized thick-walled cylinder model with a radius of $b_{i}=D / 2+d_{0}+c_{\mathrm{b}, i}(i=0,1)$ will be obtained first, as shown in Fig. 2. The concrete with an embedded bar can be modeled as a thick-wall cylinder [1-24] and the whole cracking process caused by corrosion can be divided into four stages: the free expansion stage, the stress initiation stage (see Fig. 2a), the partial cracking stage (see Figs. 2b and 2c) and the completely opened cracking caused by unstable cracking (see Fig. 2d).

The analytical solution is developed by considering the following conditions: (1) the force equilibrium in the tangential direction, (2) volume expansion in the steel-rust-concrete interface, (3) deformation compatibility in the steel-rust-concrete interface, and (4) the force equilibrium in the radial direction.

3.1 Force equilibrium in the tangential direction

During the free expansion stage, a porous zone, which is caused by entrapped or entrained air that voids around the interface between steel and concrete, is assumed to exist [1]. The corrosion product can diffuse into the capillary voids in the cement paste [1, 2]. After the initiation of steel corrosion, the penetration of corrosion products into the porous zone of concrete and the formation of a corrosion layer at the steel/concrete interface proceed simultaneously [25-26]. While the corrosion products penetrating into the porous zone will not generate extra stresses to the surrounding concrete and the volume increase is compensated by a filling up of the porous zone.

\subsubsection{Stress initiation stage}


The expansion of the corrosion products at the steel/concrete interface is restrained by the surrounding concrete. Further production of corrosion products will develop an expansive pressure $P_{\text {rust, } i}$ on the concrete, as shown in Fig. 2a. Indeed corrosion and the distribution of corrosion products in corroded rebar do not occur uniformly in practice and non-uniform corrosion around the rebar is commonly found in real situations [18]. The non-uniform corrosion problem has been studied by finite element methods [27-31] or experimental method [32]. However, for the sake of simplicity, the porous zone around the steel bar and the expansive pressure exerted on the surrounding concrete are both assumed to be uniformly distributed in the tangential direction $[1,21]$ in this paper.

In this period, the linear elastic mechanics is employed to analyze the concrete cylinder. The stresses, strains and displacements of a thick-walled cylinder subjected to internal radial pressure can be expressed as [33]

$$
\begin{aligned}
& \left\{\begin{array}{l}
\sigma_{r, i}(r)=\frac{a^{2} P_{\mathrm{rust}, i}}{b_{i}^{2}-a^{2}}\left(1-\frac{b_{i}^{2}}{r^{2}}\right) \\
\sigma_{\theta, i}(r)=\frac{a^{2} P_{\mathrm{rust}, i}}{b_{i}^{2}-a^{2}}\left(1+\frac{b_{i}^{2}}{r^{2}}\right)
\end{array}\right. \\
& \left\{\begin{array}{l}
\varepsilon_{r, i}(r)=\frac{a^{2} P_{\mathrm{rust}, i}}{\left(b_{i}^{2}-a^{2}\right) E_{\mathrm{c}, \mathrm{ff}}}\left(1-v_{\mathrm{c}}+\frac{v b_{i}^{2}}{r^{2}}\right) \\
\varepsilon_{\theta, i}(r)=\frac{a^{2} P_{\mathrm{rust}, i}}{\left(b_{i}^{2}-a^{2}\right) E_{\mathrm{c}, \mathrm{ef}}}\left[\left(1-v_{\mathrm{c}}\right)+\left(1+v_{\mathrm{c}}\right) \frac{b_{i}^{2}}{r^{2}}\right] \\
u_{i}(r)=\frac{a^{2} r P_{\mathrm{rust}, i}}{\left(b_{i}^{2}-a^{2}\right) E_{\mathrm{c}, \mathrm{ef}}}\left[\left(1-v_{c}\right)+\left(1+v_{\mathrm{c}}\right) \frac{b_{i}^{2}}{r^{2}}\right]
\end{array}\right.
\end{aligned}
$$

where $a=D / 2+d_{0}, v_{\mathrm{c}}$ is the Poisson's ratio of concrete, $E_{\mathrm{c} \text {, ef }}=E_{\mathrm{c}} /\left(1+\varphi_{\mathrm{cr}}\right)$ is an effective elastic modulus of concrete, $E_{\mathrm{c}}$ is the elastic modulus of concrete, $\varphi_{\mathrm{cr}}$ is the creep coefficient of concrete, $\sigma_{r, i}(r)$ and $\sigma_{\theta, i}(r)$ are the radial and tangential stresses, respectively, $\varepsilon_{r, i}(r)$ and $\varepsilon_{\theta, i}(r)$ 
are the radial and tangential strains, respectively, and $u_{i}(r)$ is the radial deformation.

It should be noted that, in the indoor accelerated corrosion tests, as the time to cover cracking caused by the corrosion of steel bar usually only takes a few months, the elastic modulus of concrete is unaffected by aging and can be treated as a time-independent material property, i.e. $\varphi_{\mathrm{cr}}=0$.

Then, the tangential strain of concrete in the steel-concrete interface can be expressed as

$$
\varepsilon_{\theta, i}(a)=\frac{a^{2} P_{\text {rust }, i}}{\left(b_{i}^{2}-a^{2}\right) E_{\text {c,ef }}}\left[\left(1-v_{\mathrm{c}}\right)+\left(1+v_{\mathrm{c}}\right) \frac{b_{i}^{2}}{a^{2}}\right]
$$

Cracks start to occur when the tangential tensile strain at the steel-concrete interface has reached the ultimate tensile strain, that is

$$
\varepsilon_{\theta, i}(a)=\varepsilon_{\mathrm{ct}}
$$

where $\varepsilon_{\mathrm{ct}}$ is the ultimate tensile strain of concrete, which can be obtained by Hooke's law $\varepsilon_{\mathrm{ct}}=f_{\mathrm{t}} / E_{\mathrm{c}, \mathrm{ef}}$, where $f_{\mathrm{t}}$ is the tensile strength of concrete.

\subsubsection{Partial cracking stage}

The radial pressure increases with the increase of the corrosion products and, when the internal tensile stress in the tangential direction reaches the tensile strength of concrete, cracks are initiated from the steel-concrete interface and propagate towards the concrete cover surface. The smeared crack model is employed in this study and the average strains and stresses in the tangential direction are used in the formulation. The cracks in the concrete cylinder propagate along the radial direction and stop at $r_{0, i}\left(a<r_{0, i}<b_{i}\right)$ to reach a state of equilibrium. Thus, the thick-walled cylinder can be divided into two coaxial cylinders, the inner cracked one $\left(a<r<r_{0, i}\right)$ and the outer uncracked one $\left(r_{0, i}<r<b_{i}\right)$, as shown in Figs. 2b and 
2c. The uncracked concrete is considered as an anisotropic linear elastic material. The tension softening effect is considered in the cracked concrete cylinder in which the tangential stiffness reduces gradually from the concrete-steel interface to the inner wall of the uncracked cylinder.

The corrosion product-induced expansive pressure $P_{\text {rust, } i}$ is resisted by the confining pressure $P_{\mathrm{c}, i}$ developed in the uncracked concrete cylinder together with the residual tensile stress $\sigma_{\theta, i}(r)$ provided by the cracked concrete cylinder. Thus, the force equilibrium condition can be expressed as [8-9]

$$
P_{\mathrm{rust}, i} a=P_{\mathrm{c}, i} r_{0, i}+\int_{a}^{r_{0, i}} \sigma_{\theta, i}(r) \mathrm{d} r
$$

For the uncracked cylinder $\left(r_{0, i} \leq r \leq b_{i}\right)$, the tangential force provided by the residual tensile stress $\sigma_{\theta, i}(r)$ is in equilibrium with the confining pressure $P_{\mathrm{c}, i}$; hence

$$
\sigma_{\theta, i}(r)=\frac{r_{0, i}^{2} P_{c, i}}{b_{i}^{2}-r_{0, i}^{2}}\left(1+\frac{b_{i}^{2}}{r^{2}}\right)
$$

and the boundary condition is

$$
\sigma_{\theta, i}\left(r_{0, i}\right)=f_{\mathrm{t}}
$$

By equating Eq. (9) to Eq. (8), the confining pressure $P_{\mathrm{c}, i}$ provided by the uncracked cylinder can be obtained

$$
P_{\mathrm{c}, i}=f_{\mathrm{t}} \frac{b_{i}^{2}-r_{0, i}^{2}}{b_{i}^{2}+r_{0, i}^{2}}
$$

Considering a bilinear softening behavior of concrete, as shown in Fig. 3, the relationship between the tangential stress and tangential strain of concrete under tension [34] can be expressed as 


$$
\begin{cases}\sigma_{\theta, i}(r)=E_{\mathrm{c}} \varepsilon_{\theta, i}(r) & \varepsilon_{\theta, i}(r) \leq \varepsilon_{\mathrm{ct}} \\ \sigma_{\theta, i}(r)=f_{\mathrm{t}}\left[1-0.85 \cdot \frac{\varepsilon_{\theta, i}(r)-\varepsilon_{\mathrm{ct}}}{\varepsilon_{1}-\varepsilon_{\mathrm{ct}}}\right] & \varepsilon_{\mathrm{ct}}<\varepsilon_{\theta, i}(r) \leq \varepsilon_{1} \\ \sigma_{\theta, i}(r)=0.15 f_{\mathrm{t}} \frac{\varepsilon_{\mathrm{u}}-\varepsilon_{\theta, i}(r)}{\varepsilon_{\mathrm{u}}-\varepsilon_{1}} & \varepsilon_{1}<\varepsilon_{\theta, i}(r) \leq \varepsilon_{\mathrm{u}}\end{cases}
$$

Cracks start to occur when the tangential tensile strain at the steel-concrete interface has reached the ultimate tensile strain, $\varepsilon_{\mathrm{ct}}$. Further expansion of the corrosion products causes the tangential tensile strain of concrete in the steel-rust-concrete interface to change from $\varepsilon_{\mathrm{ct}}<\varepsilon_{\theta, i}(a)<\varepsilon_{1}$ to $\varepsilon_{1}<\varepsilon_{\theta, i}(a)<\varepsilon_{\mathrm{u}}$. Hence, the partial cracking stage can be divided into the first partial cracking stage $\left(\varepsilon_{\mathrm{ct}} \leq \varepsilon_{\theta, i}(a) \leq \varepsilon_{1}\right)$ and the second partial cracking stage $\left(\varepsilon_{1} \leq \varepsilon_{\theta, i}(a) \leq \varepsilon_{\mathrm{u}}\right)$, as shown in Figs. 2b and 2c, respectively.

The bilinear softening curve is used to describe the residual tensile strength of concrete as a function of a fictitious crack opening $w$. The coordinates of the fictitious crack opening $w_{1}$ and $w_{\mathrm{u}}$ can be taken as $\sigma_{\theta, i}(r)=0.15 f_{\mathrm{t}}$ and $\sigma_{\theta, i}(r)=0$, respectively, in the softening curve [34]. Based on the previous test results [7, 35], $w_{1}$ and $w_{\mathrm{u}}$ are approximately equal to $0.03 \mathrm{~mm}$ and $0.2 \mathrm{~mm}$, respectively. In the present study, the corresponding strains $\varepsilon_{1}$ and $\varepsilon_{\mathrm{u}}$ are calculated based on the characteristic crack-band width $h_{\mathrm{c}}$ to account for the size effect so that $\varepsilon h_{\mathrm{c}}=w$. Bažant and Oh [36] suggested that $h_{\mathrm{c}}$ is approximately equal to $4 d_{a}$, where $d_{a}$ is the maximum aggregate size, which is taken as $20 \mathrm{~mm}$ in this study. Therefore, $\varepsilon_{1}=0.000375$ and $\varepsilon_{\mathrm{u}}=$ 0.0025 .

\subsubsection{First stage of partial cracking $\left(\varepsilon_{\mathrm{ct}} \leq \varepsilon_{\theta, i}(a) \leq \varepsilon_{1}\right)$}

At the first stage of partial cracking, the tangential stress of concrete at radius $r_{0, i}$ is $f_{\mathrm{t}}$ and the stresses of cracked concrete are less than $f_{\mathrm{t}}$. As the smeared crack model is employed, the 
total crack openings can be obtained by integrating the exceedance of the average tangential tensile strain with the cracking strain along the tangential direction of the cracked cylinder. Hence, the total crack openings $w_{i}(r)$ at a ring with a radius $r$, can be expressed as

$$
2 \pi r\left[\varepsilon_{\theta, i}(r)-\varepsilon_{\mathrm{ct}}\right]=w_{i}(r)
$$

In order to calculate the tangential stress distribution in the cracked cylinder, we assume that $w_{i}(r)$ decreases linearly along the radial direction from $w_{i}(a)$ at $r=a$ to 0 at $r_{0, i}$. Thus, the total crack openings can be expressed as

$$
w_{i}(r)=\frac{w_{i}(a)\left(r_{0, i}-r\right)}{r_{0, i}-a}
$$

Equating Eq. (13) to Eq. (12), the strain of concrete in the cracked cylinder along the radial direction can be obtained

$$
\varepsilon_{\theta, i}(r)=\frac{w_{i}(a)\left(r_{0, i}-r\right)}{2 \pi r\left(r_{0, i}-a\right)}+\varepsilon_{\mathrm{ct}}
$$

Equating Eq. (14) to Eq. (11), the confining pressure caused by the residual tensile stress $\sigma_{\theta, i}(r)$ can be obtained

$$
\int_{a}^{r_{0, i}} \sigma_{\theta, i}(r) \mathrm{d} r=f_{t}\left[r_{0, i}-a-\frac{0.85 w_{i}(a)\left(r_{0, i} \ln \frac{r_{0, i}}{a}-r_{0, i}+a\right)}{2 \pi\left(r_{0, i}-a\right)\left(\varepsilon_{1}-\varepsilon_{c t}\right)}\right]
$$

At the end of this stage, when $\sigma_{\theta, i}(a)=0.15 f_{\mathrm{t}}$, the crack opening is at $r=a$ is $w_{1, i}(a)$ and the crack front is at $r_{1, i}$, as shown in Fig. 4a. The radial distance resulting in the tangential stress in concrete decreasing from $f_{\mathrm{t}}$ to $0.15 f_{\mathrm{t}}$ is $r_{1, i}-a$.

\subsubsection{Second stage of partial cracking $\left(\varepsilon_{1} \leq \varepsilon_{\theta, i}(a) \leq \varepsilon_{\mathrm{u}}\right)$}

In the second stage of partial cracking, we assume that the radial distance resulting in the 
tangential stress of concrete decreasing from $f_{\mathrm{t}}$ to $0.15 f_{\mathrm{t}}$ is the same as that for the first stage of partial cracking (see Fig. 4) when the crack is continuously penetrating into the concrete. The continuity of stress and strain on the common boundary between the uncracked and cracked concrete cylinders is maintained. The total crack openings at radius $r_{0, i}-r_{1, i}+a$ at the second stage of partial cracking and at radius $a$ at the first stage of partial cracking are expressed in Eqs. (16) and (17), respectively.

$$
\begin{gathered}
w_{1, i}\left(r_{0, i}-r_{1, i}+a\right)=2 \pi\left(r_{0, i}-r_{1, i}+a\right)\left(\varepsilon_{1}-\varepsilon_{\mathrm{ct}}\right) \\
w_{1, i}(a)=2 \pi a\left(\varepsilon_{1}-\varepsilon_{\mathrm{ct}}\right)
\end{gathered}
$$

By equating the strains at radius $r_{0, i}-r_{1, i}+a$ at the second stage of partial cracking and at radius $a$ at the first stage of partial cracking, and using Eq. (17) and Eq. (16), one can have

$$
w_{1, i}\left(r_{0, i}-r_{1, i}+a\right)=\frac{\left(r_{0, i}-r_{1, i}+a\right) w_{1, i}(a)}{a}
$$

As shown in Figs. 2c and 4b, the cracked cylinder is divided into two parts: the inner cracked part $\left(a \leq r \leq r_{0, i}-r_{1, i}+a\right)$ and the outer cracked part $\left(r_{0, i}-r_{1, i}+a \leq r \leq r_{0, i}\right)$. In order to calculate the tangential stress distribution in the cracked cylinder, it is assumed that the total crack openings $w_{i}(r)$ decrease linearly in the two parts, respectively, along the radial direction. Therefore, the total crack openings along the wall of the cracked cylinder can be expressed as

$$
\begin{cases}w_{i}(r)=\frac{w_{i}(a)\left(r_{0, i}-r_{1, i}+a-r\right)+w_{1, i}\left(r_{0, i}-r_{1, i}+a\right)(r-a)}{r_{0, i}-r_{1, i}} & a \leq r \leq r_{0, i}-r_{1, i}+a \\ w_{i}(r)=\frac{w_{1, i}\left(r_{0, i}-r_{1, i}+a\right)\left(r_{0, i}-r\right)}{r_{1, i}-a} & r_{0, i}-r_{1, i}+a \leq r \leq r_{0, i}\end{cases}
$$

By equating Eq. (19) and Eq. (12), the strain of concrete in the tangential direction in the cracked cylinder can be obtained 


$$
\begin{cases}\varepsilon_{\theta, i}(r)=\frac{w_{i}(a)\left(r_{0, i}-r_{1, i}+a-r\right)+w_{1, i}\left(r_{0, i}-r_{1, i}+a\right)(r-a)}{2 \pi r\left(r_{0, i}-r_{1, i}\right)}+\varepsilon_{\mathrm{ct}} & a \leq r \leq r_{0, i}-r_{1, i}+a \\ \varepsilon_{\theta, i}(r)=\frac{w_{1, i}\left(r_{0, i}-r_{1, i}+a\right)\left(r_{0, i}-r\right)}{2 \pi r\left(r_{1, i}-a\right)}+\varepsilon_{\mathrm{ct}} & r_{0, i}-r_{1, i}+a \leq r \leq r_{0, i}\end{cases}
$$

By equating Eq. (20) and Eq. (11), the confining pressure developed by the residual tensile stress $\sigma_{\theta, i}(r)$ can then be obtained

$$
\begin{aligned}
\int_{a}^{r_{0, i}} \sigma_{\theta, i}(r) \mathrm{d} r & =\frac{0.15 f_{\mathrm{t}}}{\varepsilon_{\mathrm{u}}-\varepsilon_{1}}\left\{-\frac{1}{2 \pi}\left[w_{i}(a)+a \cdot \frac{w_{i}(a)-w_{1, i}\left(r_{0, i}-r_{1, i}+a\right)}{r_{0, i}-r_{1, i}}\right] \ln \frac{r_{0, i}-r_{1, i}+a}{a}\right] \\
& +f_{\mathrm{t}}\left[\left(r_{1, i}-a\right)-0.85 \cdot \frac{w_{1, i}\left(r_{0, i}-r_{1, i}+a\right)\left(r_{0, i} \ln \frac{r_{0, i}}{r_{0, i}-r_{1, i}+a}-r_{1, i}+a\right)}{2 \pi\left(r_{1, i}-a\right)\left(\varepsilon_{1}-\varepsilon_{\mathrm{ct}}\right)}\right] \\
& {\left[\begin{array}{l}
2 \pi \\
\left.r_{1, i}+a\right)
\end{array}\right] }
\end{aligned}
$$

\subsubsection{Unstable cracking}

As the expansive pressure increases, cracks propagate unstably through the cover when the value of the expansive pressure reaches the maximum value. Cracks would then appear on the surface of concrete cover (see Fig. 2d).

\subsection{Volume expansion in the steel-rust-concrete interface}

In the stress initiation stage, the net volume of corrosion product $V_{\text {net, } i}$ which causes pressure on the surrounding concrete is summarized as follows

$$
V_{\text {net }, i}=V_{\text {rust }, i}-V_{\text {steel }, i}-V_{\text {porous }, i}
$$

where $V_{\text {rust }, i}$ is the total volume of corrosion product, $V_{\text {steel }, i}$ is the volume of consumed steel and $V_{\text {porous,i }}$ is the volume of corrosion product that penetrates into the porous zone. 
Once the internal tensile stress in the tangential direction exceeds the tensile strength of concrete, cracks will occur in the concrete cylinder. In the partial cracking or completely opened cracking stage, some rust will penetrate into the corrosion-caused cracks [17, 19, 25]. Then the net volume of corrosion product $V_{\text {net, } i}$ that generates pressure on the surrounding concrete becomes

$$
V_{\text {net }, i}=V_{\text {rust }, i}-V_{\text {steel }, i}-V_{\text {porous }, i}-\lambda V_{\text {crack }, i}
$$

where $V_{\text {crack,i }}$ is the volume of cracks and $\lambda(0 \leq \lambda)$ is a ratio defining the volume of corrosion products diffused into the cracks.

The ratio of volume of corrosion product $V_{\text {rust }, i}$ to that of its original steel $V_{\text {steel, } i}$ is defined as $\beta$

$$
\beta=\frac{V_{\text {rust }, i}}{V_{\text {steel }, i}}
$$

Depending on the level of oxidation, $\beta$ may vary from 1.7 to 6.15 (for example, $\mathrm{FeO}=1.7$, $\mathrm{Fe}_{3} \mathrm{O}_{4}=2, \mathrm{Fe}_{2} \mathrm{O}_{3}=2.1, \alpha-\mathrm{FeO}(\mathrm{OH})=2.95, \beta-\mathrm{FeO}(\mathrm{OH})=3.53, \mathrm{Fe}(\mathrm{OH})_{2}=3.6, \gamma-\mathrm{FeO}(\mathrm{OH})=3.07$, $\left.\mathrm{Fe}(\mathrm{OH})_{3}=4.0, \mathrm{Fe}(\mathrm{OH})_{3} 3 \mathrm{H}_{2} \mathrm{O}=6.15[1,37]\right)$. Furthermore, $\beta$ can be expressed as

$$
\beta=\frac{M_{\text {rust }, i} \rho_{\text {steel }}}{\rho_{\text {rust }} M_{\text {steel }, i}}
$$

where $M_{\text {rust, } i}$ and $M_{\text {steel, } i}$ are the masses of rust and the steel consumed to produce $M_{\text {rust, }, i}$ respectively, and $\rho_{\text {rust }}$ and $\rho_{\text {steel }}$ are the densities of rust and steel, respectively.

Liu and Weyers [1] have given the relationship between $M_{\text {rust,i }}$ and $M_{\text {steel, } i}$ as follows

$$
M_{\text {steel }, i}=\alpha M_{\text {rust }, i}
$$

where $\alpha$ is the ratio of molecular mass of steel to molecular mass of rust. As the molar mass of $\mathrm{Fe}$ is $55.85 \mathrm{~g}, \mathrm{O}_{2}$ is $32 \mathrm{~g}$ and $\mathrm{H}_{2}$ is $2 \mathrm{~g}$, it can be shown that the ratio $\alpha$ varies from 0.348 
$\left(\mathrm{Fe}(\mathrm{OH})_{3} 3 \mathrm{H}_{2} \mathrm{O}\right)$ to $0.778(\mathrm{FeO})$ for the composition of rust products, as mentioned.

Liu and Weyer [1] obtained the mass of corrosion product $M_{\text {rust, } i}$ as

$$
M_{\text {rust }, i}^{2}=\frac{2 \times 0.098 \pi D}{\alpha} \int_{0}^{t_{i}} i_{\text {cor }} \mathrm{d} t
$$

where $i_{\text {cor }}$ is the annual mean corrosion rate $\left(\mu \mathrm{m} / \mathrm{cm}^{2}\right)$ and $t_{i}$ is the corrosion time (years).

As the porous zone that is assumed around the steel bar and the expansive pressure exerted on the surrounding concrete are both assumed to be uniform [1], $V_{\text {net, } i}$ and $V_{\text {porous }, i}$ can be determined as follows $[2,18]$

$$
\begin{aligned}
& V_{\text {net }, i}=\pi d_{\mathrm{f}, i}\left(D+2 d_{0}+d_{\mathrm{f}, i}\right) \\
& V_{\text {porous }, i}=\pi d_{0}\left(D+d_{0}\right)
\end{aligned}
$$

The ability of the porous zone (capillaries and air voids) to accommodate the corrosion products can prolong the time to damaging of the concrete cover, at least in the initial corrosion stage. Many researchers have attempted to determine the thickness of the porous zone $d_{0}$ using numerical and experimental methods. Liu and Weyers [1] suggested that $d_{0}$ could be obtained through the difference between the numerical and experimental results and estimated $d_{0}=12.5 \mu \mathrm{m}$. Using a similar method, $d_{0}$ was found to range from $20 \mu \mathrm{m}$ to 120 $\mu \mathrm{m}$ by various researchers $[16,38]$. El Maaddawy and Soudki [6] took $d_{0}$ to be in the range of 10 to $20 \mu \mathrm{m}$.

The volume of cracks $V_{\text {crack,i }}$ can be calculated by multiplying the total width openings by the depth of cracks in the first stage of partial cracking

$$
V_{\text {crack }, i}=\frac{\left(r_{0, i}-a\right) w_{i}(a)}{2}
$$

Similarly, $V_{\text {crack,i }}$ in the second stage of partial cracking can be obtained as 


$$
V_{\text {crack }, i}=\left[\frac{w_{1, i}\left(r_{0, i}-r_{1, i}+a\right)\left(r_{1, i}-a\right)}{2}+\frac{w_{1, i}\left(r_{0, i}-r_{1, i}+a\right)+w_{i}(a)}{2}\left(r_{0, i}-r_{1, i}\right)\right]
$$

and $V_{\text {crack,i }}$ in the stage of completely opened cracking is given as

$$
V_{\text {crack }, i}=\left[\frac{w_{1, i}\left(b-r_{2, i}\right)+w_{i}(a)}{2}\left(b-r_{2, i}-a\right)+\frac{w_{1, i}\left(b-r_{2, i}\right)+w_{i}(b)}{2} r_{2, i}\right]
$$

The ratio $\lambda$ plays an important role in the prediction of the time to cover cracking and the amount of steel consumed [20]. However, the test data of $\lambda$ is not available yet and different values have been proposed in the literature. Shodja et al. [19-20] compared the experimental and predicted results relating to the amount of consumed rebar and obtained $\lambda=0.33$. They also found that $\lambda$ was related to the material properties of concrete (such as the Poisson's ratio, tensile strength, residual tensile strength and the initial elasticity modulus of concrete) and the chemical components of corrosion products. Wong et al. [39] found that a relatively large amount of rust could be transported through radial cracks. However, Ožbolt et al. [40] argued that this transport was very much dependent on the level of water saturation. Zhao et al. [25, 41] observed that corrosion products did not fill the corrosion-induced cracks and they also found some corrosion products penetrated into the concrete on both sides of cracks. Some other researchers $[17-18,21]$ have assumed that the corrosion products could fill up all the space of cracks and adopted $\lambda=1$. In this study, $\lambda$ is chosen as 0.45 in the subsequent analysis.

3.3 Deformation compatibility and force equilibrium in the radial direction

To simulate the corrosion-caused cracking in RC structures, a two-phase mechanical system $[22,24]$, which is composed of corrosion products with non-corroded steel as one integrated phase (or a composite) and concrete as another phase, is employed. With the increase in 
corrosion product, the corrosion products and non-corroded steel are combined together to form a steel-corrosion product composite, which can be regarded as a cylinder subjected to a restraining pressure $P_{\text {rust }, i}$.

The compaction of the corrosion product layer due to the concrete restraining pressure [13, 17] is considered in this study. When the porous zone has been fully filled with the corrosion products, the diameter of steel-corrosion product composites, $D_{\mathrm{r}, i}$, under the compressive pressure caused by the surrounding concrete is

$$
D_{\mathrm{r}, i}=D+2 d_{0}+2 d_{\mathrm{c}, i}
$$

where $d_{c, i}$ is the actual deformation in the radial direction of the steel-corrosion product composites at the steel-rust-concrete interface.

The tangential elongation of concrete in the steel-rust-concrete interface $L_{c, i}$ can be expressed as

$$
L_{\mathrm{c}, i}=2 \pi a \varepsilon_{\theta, i}(a)=\pi D_{\mathrm{r}, i}-\pi\left(D+2 d_{0}\right)
$$

in which $\varepsilon_{\theta, i}(a)$ is the tangential strain of concrete in the steel-rust-concrete interface and can be expressed as follows

$$
\varepsilon_{\theta, i}(a)=d_{\mathrm{c}, i} / a
$$

Owing to the confinement effect, the free-expansion deformation $d_{\mathrm{f}, i}$ of the steel-corrosion product composite is reduced to $d_{c, i}$, as shown in Fig. 5. Invoking the deformability compatibility at the steel-rust-concrete interface in the radial direction

$$
d_{\mathrm{f}, i}=d_{\mathrm{s}, i}+d_{\mathrm{c}, i}
$$

where $d_{\mathrm{s}, i}$ is the deformation of the steel-corrosion product composite cause by the restraining pressure. 
For the cracked concrete, the radial stiffness is assumed to be the same as that of the uncracked concrete. Hence, the expansive pressure caused by corrosion can be obtained from Eq. (4)

$$
P_{r u s t, i}=\frac{d_{c, i}\left(b_{i}^{2}-a^{2}\right) E_{c, e f}}{a\left[a^{2}+b_{i}^{2}+\left(b_{i}^{2}-a^{2}\right) v_{c}\right]}
$$

At the same time, the steel-corrosion product composite is subjected to the same restraining pressure. Assuming that the composite is a linear isotropic material, the restraining pressure caused by the surrounding concrete leads to the deformation of the composite, $d_{\mathrm{s}, i}$, and the pressure can be expressed as [33]

$$
P_{\mathrm{rust}, i}=\frac{d_{\mathrm{s}, i} E_{\mathrm{s}, \mathrm{eq}, i}}{\left(a+d_{\mathrm{f}, i}\right)\left(1-v_{\mathrm{e}, \mathrm{eq}}\right)}
$$

where $E_{\mathrm{s}, \mathrm{eq}, i}$ and $v_{\mathrm{e}, \mathrm{eq}}$ are the elastic modulus and the Poisson's ratio of the composite, respectively.

In order to calculate the elastic modulus of the composite, the amount of consumed steel bar is given by [22, 24]

$$
\gamma_{1, i}=\frac{4 V_{\text {steel }, i}}{\pi D^{2}}
$$

In the stress initiation stage, the elastic modulus of the composite can be determined based on the volume fraction as $[22,24]$

$$
E_{\mathrm{s}, \mathrm{eq}, i}=\frac{1+(\beta-1) \gamma_{1, i}}{\left(1-\gamma_{1, i}\right) / E_{\mathrm{s}}+\gamma_{1, i} \beta / E_{\mathrm{r}}}
$$

where $E_{\mathrm{s}}$ and $E_{\mathrm{r}}$ are the elastic moduli of steel and corrosion product, respectively.

After the initiation of cracks at the steel-rust-concrete interface, some corrosion products would penetrate into the cracks; these corrosion products cannot generate pressure on the surrounding concrete and should be removed from the calculation of the elastic modulus of 
the combination. Hence, the effective amount of consumed steel bar in the first stage of partial cracking can be expressed as

$$
\gamma_{2, i}=\frac{4 \beta V_{\text {steel }, i}-2 \lambda w_{i}(a)\left(r_{0, i}-a\right)}{\beta \pi D^{2}}
$$

The effective amount of consumed steel bar in the second stage of partial cracking can be expressed as

$$
\gamma_{2, i}=\frac{4 \beta V_{\text {steel }, i}-4 \lambda\left[\frac{w_{1, i}\left(r_{0, i}-r_{1, i}+a\right)\left(r_{1, i}-a\right)}{2}+\frac{w_{1, i}\left(r_{0, i}-r_{1, i}+a\right)+w_{i}(a)}{2}\left(r_{0, i}-r_{1, i}\right)\right]}{\beta \pi D^{2}}
$$

Furthermore, the effective amount of consumed steel bar in the stage of completely opened cracking can be expressed as

$$
\gamma_{2, i}=\frac{4 \beta V_{\text {steel }, i}-4 \lambda\left[\frac{w_{1, i}\left(b_{i}-r_{2, i}\right)+w_{i}(a)}{2}\left(b_{i}-r_{2, i}-a\right)+\frac{w_{1, i}\left(b_{i}-r_{2, i}\right)+w_{i}\left(b_{i}\right)}{2} r_{2, i}\right]}{\beta \pi D^{2}}
$$

In the stages of partial cracking and completely opened cracking, the effective elastic modulus can be calculated based on the volume fraction, as follows

$$
E_{\mathrm{s}, \mathrm{eq}, i}=\frac{1-\gamma_{1, i}+\gamma_{2, i} \beta}{\left(1-\gamma_{1, i}\right) / E_{\mathrm{s}}+\left(\gamma_{2, i} \beta / E_{\mathrm{r}}\right)}
$$

The elastic modulus of corrosion product is an important parameter which may greatly influence the expansive pressure caused by steel corrosion in the analytical and numerical models. However, a wide range of elastic modulus of rust can be found in the literature. Caré et al. [42] found that the elastic modulus of rust was not constant but rather would increase with time. Hosemann et al. [43] developed nano-indentation tests on the rust samples and showed that the range of elastic modulus values was 70-100 GPa. Bhargava et al. $[2,10]$ took the effective elastic modulus of the steel-rust product composites as $210 \mathrm{GPa}$ which is the 
same as that of reinforcement. Lundgren [44-45] and Ouglova et al. [46] assumed that rust behaved like a granular material and its stiffness increased with stress level. In recent studies, Zhao et al. [47, 48] reported that the measured elastic modulus of naturally generated corrosion products varied from $48 \mathrm{GPa}$ to $100 \mathrm{MPa}$. In this study, $E_{r}$ is taken as $80 \mathrm{GPa}$. The effects of variations of $E_{r}$ on the critical volume of consumed steel, the critical expansive pressure and the time to cover cracking for different tensile strengths of concrete will be presented in Section 4.2.4.

\section{Results and discussion}

4.1 Calibration of the confinement adjustment factors

By comparing the measured and predicted time to cover cracking, the confinement adjustment factors $\left(\psi_{c}, \psi_{v}, \psi_{p}\right.$ and $\left.\psi_{t}\right)$ corresponding to various cover thickness ratios $c_{\mathrm{t}} / c_{\mathrm{b}}$ can be obtained. Table 1 presents the key experimental parameters of the selected test specimens $[1,49]$ for calibration of the time to cover cracking.

The numerical models have been established based on the theory described in Sections 2 and 3 for calculating the time to cover cracking. As the measured time to cover cracking of the specimens was only in the range of 0.011-3.54 years, the effect of creep of concrete is ignored in this study. Hence, $\varphi_{\mathrm{cr}}$ is taken as zero in the model. For the specimens from Liu and Weyers [1], other parameters used in the model are listed as follows: $E_{\mathrm{s}}=200 \mathrm{GPa}, E_{\mathrm{r}}=$ $80 \mathrm{GPa}, \rho_{\text {rust }}=3600 \mathrm{~kg} / \mathrm{m}^{3}[1], \rho_{\text {steel }}=7850 \mathrm{~kg} / \mathrm{m}^{3}[1], d_{0}=16 \mu \mathrm{m}[6], \varepsilon_{1}=0.000375, \varepsilon_{\mathrm{u}}=$ 0.0025, $\lambda=0.45, \beta=3$ [18], $v_{\mathrm{c}}=0.2$ and $v_{\mathrm{e}, \mathrm{eq}}=0.3$. For the specimens from $\mathrm{Vu}$ et al. [49], the same set of parameters has been used, except $d_{0}=12 \mu \mathrm{m}$ [6] and $\beta=3.5$ [18]. 
Table 2 shows the measured time to cover cracking $t_{\mathrm{c}, \mathrm{e}}$ with different ratios of $c_{\mathrm{t}} / c_{\mathrm{b}}$ and the predicted results with different values of $c_{\mathrm{b}, 1}$. The value $c_{\mathrm{b}, 1}$ is chosen such that it leads to the best predicted time to cover cracking $t_{\mathrm{c}, 1}$ when compared with the measured time $t_{\mathrm{c}, e}$. The best values of $c_{\mathrm{b}, 1}$ are $41 \mathrm{~cm}, 61 \mathrm{~cm}, 75 \mathrm{~cm}, 38 \mathrm{~cm}$ and $40 \mathrm{~cm}$ for the ratios $c_{\mathrm{t}} / c_{\mathrm{b}}=7,2.92,1.86,9$ and 9, respectively. The confinement adjustment factors subjected to different ratios of $c_{\mathrm{t}} / c_{\mathrm{b}}$ were then determined, as shown in Table 3 and Fig. 6. As shown in the figure, the confinement adjustment factor $\psi_{c}$ increases with the increase of $c_{\mathrm{t}} / c_{\mathrm{b}}$ from 1 to 7 . After that, $\psi_{c}$ reaches its maximum of approximately 1.6. The other confinement adjustment factors $\left(\psi_{v}\right.$, $\psi_{p}$ and $\psi_{t}$ ) show similar increasing trends. However, they reach their maximum limit when $C_{\mathrm{t}} / C_{\mathrm{b}}$ is approximately equal to 3 . Based on these results, simplified relationships between the confinement adjustment factors and $c_{\mathrm{t}} / c_{\mathrm{b}}$ are derived in Eq. (45).

$$
\begin{gathered}
\psi_{c}= \begin{cases}0.9 \frac{c_{\mathrm{t}}}{C_{\mathrm{b}}}+0.10 & 1 \leq c_{\mathrm{t}} / c_{\mathrm{b}} \leq 7 \\
1.6 & 7<c_{\mathrm{t}} / c_{\mathrm{b}}\end{cases} \\
\psi_{v}= \begin{cases}0.07 \frac{c_{\mathrm{t}}}{C_{\mathrm{b}}}+0.93 & 1 \leq c_{\mathrm{t}} / c_{\mathrm{b}} \leq 3 \\
1.14 & 3<c_{\mathrm{t}} / c_{\mathrm{b}}\end{cases} \\
\psi_{p}= \begin{cases}0.08 \frac{c_{\mathrm{t}}}{C_{\mathrm{b}}}+0.92 & 1 \leq c_{\mathrm{t}} / c_{\mathrm{b}} \leq 3 \\
1.15 & 3<c_{\mathrm{t}} / c_{\mathrm{b}}\end{cases} \\
\psi_{t}= \begin{cases}0.15 \frac{c_{\mathrm{t}}}{C_{\mathrm{b}}}+0.85 & 1 \leq c_{\mathrm{t}} / c_{\mathrm{b}} \leq 3 \\
1.3 & 3<c_{\mathrm{t}} / c_{\mathrm{b}}\end{cases}
\end{gathered}
$$

The present results indicate that the critical volume of consumed steel $V_{\text {steel, }}$, the critical expansive pressure $P_{\text {rust }}$ and the time to cover cracking $t_{\mathrm{c}}$ are significantly affected by $c_{t} / c_{b}$ when the ratio is less than 3.0. This is attributed to the fact that, the larger the cover thickness 
ratio $c_{t} / c_{b}$, the higher the expansive pressure that can be resisted by the concrete and the longer the time required to cause cover cracking.

\subsection{Parametric study}

The corrosion of RC structures can be influenced by various factors. In this section, the variations of smeared crack propagation, volume of consumed steel and corrosion-caused expansive pressure with time, respectively, for the traditional analytical model $\left(c_{t} / c_{b}=1\right)$ are investigated. Furthermore, the ratio of cover thickness to reinforcing bar diameter, tensile strength of concrete, mechanical behavior and chemical composition of rust and $\lambda$ on the critical volume of consumed steel, critical expansive pressure and time to cover cracking caused by corrosion are studied.

\subsubsection{Effects of time}

The variations of smeared crack propagation, volume of consumed steel and corrosioncaused expansive pressure with time, respectively, are investigated in Fig. 7. Fig. 7a shows the smeared crack propagation with time. It can be observed that crack propagation is zero in the free expansion and stress initiation stages. When the tensile stress of concrete in the tangential direction in the steel-rust-concrete interface exceeds the tensile strength of concrete, cracks start to occur. Cracks propagate in the radial direction in the cylinder wall as time increases. Fig. 7b presents the volume of consumed steel, which increases with time. Fig. 7c displays the variation of corrosion-caused expansive pressure with time. As expected, in the free expansion stage, there is no expansive pressure on the surrounding concrete. It can be seen that the expansive pressure increases with time. This trend is in line with the work of 
Balafas and Burgoyne [13]. When the expansive pressure reaches the maximum value, unstable crack propagation will happen through the whole cover to cause the cover failure as shown in Fig. 7. Zhao et al. [18] explained that as the steel corrosion grows after the free expansion, the expansion of corrosion products can cause energy accumulates in the concrete cover. When the energy of the concrete cover is greater than the energy required to lead the cover cracking, unstable crack propagation will happen to cause the cover failure.

\subsubsection{Effects of the ratio of cover thickness to reinforcing bar diameter}

The effects of the ratio of cover thickness to reinforcing bar diameter, $c_{\mathrm{b}} / D$, on the critical volume of consumed steel, critical expansive pressure and time to cover cracking are shown in Fig. 8. The critical volume of consumed steel as a function of $c_{\mathrm{b}} / D$ is shown in Fig. 8a. The figure shows that the larger the ratio $c_{\mathrm{b}} / D$ is, the larger the critical volume of consumed steel will be. Such result is concurred with the analytical findings from Alonso et al. [51] and Vidal et al. [52]. Fig. 8b presents critical expansive pressure versus $c_{\mathrm{b}} / D$. It can be observed that critical expansive pressure increases with the increasing of $c_{\mathrm{b}} / D$, which is in line with the work of Chernin et al. [16, 38]. Fig. 8c shows the effects of the ratio $c_{b} / D$ on the time to cover cracking, in which the corrosion rate is assumed to be $2.5 \mu \mathrm{A} / \mathrm{cm}^{2}$. It is found that the time to cover cracking increase as the ratio $c_{\mathrm{b}} / D$ increases. This finding is supported by the analytical result from $\mathrm{Li}$ et al. [14]. It is understandable that the larger the ratio $c_{\mathrm{b}} / D$ is, the larger the critical volume of consumed steel and longer the time to cover cracking will be.

\subsubsection{Effects of tensile strength of concrete and type of corrosion product}


Effects of tensile strength of concrete and type of corrosion product on the critical volume of consumed steel, critical expansive pressure and time to cover cracking are investigated. Fig. 9a shows the effects of the tensile strength of concrete on the critical volume of consumed steel for different types of corrosion products. It can be seen that as the tensile strength increases, the steel loss to cause the cover cracking increase, which is in line with the work of Zhao et al. [18]. It is also clear that the critical volume of consumed steel increases with the ratio of the volume of rust to the volume of consumed steel decreasing as mentioned by Liu and Weyers [1].

Fig. 9b presents the effect of the type of corrosion products on the critical expansive pressure for different tensile strength of concrete. As observed, the variation of $\beta$ has no effect on the critical expansive pressure. This is because the critical expansive pressure to cause cover cracking is controlled by the material properties of concrete and the geometrical properties of cover, but not the type of corrosion products. It is found that the critical expansive pressure increases with an increase in the tensile strength of concrete which concurs with the work of Zhao et al. [18]. This is understandable that higher concrete tensile strength can strength the bearing capacity of the concrete cover.

The time to cover cracking as a function of the tensile strength of concrete for different types of corrosion products is shown in Fig. 9c. The figure shows that the larger the tensile strength of concrete is, the longer the time to cover cracking will be. This observation is supported by the work of Liu and Weyers [1] and Bhargava et al. [2, 10, 11]. It is evident that the time to cover cracking increases with the decrease in $\beta$. This is because more corrosion products are needed to cause cover cracking for a less value of $\beta$, which can prolong the time 
to cover cracking.

\subsubsection{Effects of the elastic modulus of rust}

Effects of the elastic modulus of rust on the critical volume of consumed steel, critical expansive pressure and time to cover cracking for different tensile strengths of concrete are studied here. Figs. 10a and 10b present the effects of the elastic modulus of rust on the critical volume of consumed steel and time to cover cracking for different tensile strengths of concrete, respectively. It can be seen that both the critical volume of consumed steel and time to cover cracking decrease dramatically as the elastic modulus increases from $0.1 \mathrm{GPa}$ to 0.5 GPa. After that, with an increase of the elastic modulus from $0.5 \mathrm{GPa}$ to $200 \mathrm{GPa}$, the elastic modulus has almost no effect on the critical volume of consumed steel and time to cover cracking. This result generally concurs with that of Balafas and Burgoyne [53] in showing that an elastic modulus greater than $0.3 \mathrm{GPa}$ would not affect the critical volume of the consumed steel and time to cover cracking.

The critical expansive pressure versus elastic modulus of rust for different tensile strengths of concrete is shown in Fig. 10c. The variation of $E_{\mathrm{r}}$ has no influence on the critical expansive pressure. This is because the critical expansive pressure necessary to cause cover cracking depends only on the material properties of concrete and the geometrical properties of cover, and not on the elastic modulus of corrosion products.

\subsubsection{Effects of $\lambda$}

The effects of $\lambda$ (the ratio defining the volume of corrosion products diffused into the 
cracks) on the critical volume of consumed steel and time to cover cracking are shown in Figs. 11a and 11b, respectively. It can be seen that the critical volume of consumed steel and time to cover cracking increase with that of $\lambda$. This is because more steel is needed to be consumed to generate the corrosion products to fill up the required space in a crack prior to cover cracking. It is noted that similar findings were also reported by Shodja and Kiani [19-20].

\section{Conclusions}

In the present study, a double-cylinder model is proposed with the consideration of the concrete confinement effect outside the cylinders, to simulate the cracking of cover caused by the corrosion of reinforcing bars. The analytical solution of this model is developed with the consideration of the following conditions: (1) force equilibrium in the tangential and radial directions, (2) volume expansion in the steel-rust-concrete interface, and (3) deformation compatibility in the steel-rust-concrete interface. Furthermore, the residual tensile stress in cracked concrete and the stiffness contribution from both reinforcement and corrosion products have been considered, and the continuity of stress and strain on the common boundary between the uncracked and cracked concrete cylinders is maintained.

Four confinement adjustment factors $\left(\psi_{c}, \psi_{v}, \psi_{p}\right.$ and $\left.\psi_{t}\right)$ are introduced to account for the confinement effects outside the concrete cylinder. Such factors have been calibrated through the available tests. It can be seen that all the confinement adjustment factors increase initially with the increase of the cover thickness ratio $c_{t} / c_{b}$ and reach certain limits when $c_{t} / c_{b}$ further increases. Furthermore, the cover thickness ratio is found to have a significant effect on the

critical volume of consumed steel $V_{\text {steel }}$, the critical expansive pressure $P_{\text {rust }}$ and the time to 
cover cracking $t_{\mathrm{m}}$, and they all increase with that of $c_{t} / c_{b}$ until this ratio reaches 3.0.

Furthermore, a numerical parametric study has been conducted and the effects of the ratio of cover thickness to reinforcing bar diameter, tensile strength of concrete, mechanical behavior and chemical composition of rust, and volume of corrosion products diffused into the cracks, critical expansive pressure and time to cover cracking caused by corrosion have been investigated in detail.

Finally, to apply the proposed model to solving practical problems, the following steps can be adopted:

1. The time to cover cracking, critical volume of consumed steel and critical expansive pressure for a thick-walled cylinder model with a radius of $b_{0}=D / 2+d_{0}+c_{\mathrm{b}, 0}$, where $c_{\mathrm{b}, 0}=c_{\mathrm{b}}$ is the thickness of the thinner cover, can be obtained from Section 3 or from corresponding cylinder-specimen test results;

2. Based on the ratio $c_{t} / c_{b}$, appropriate confinement adjustment factors $\left(\psi_{c}, \psi_{v}, \psi_{p}\right.$ and $\left.\psi_{t}\right)$ can be obtained from Eq. (45);

3. Using Eq. (1), the actual critical volume of consumed steel, critical expansive pressure and time to cover cracking of the RC structure can be determined.

\section{Acknowledgement}

The research described here was supported by the Seed Funding Programme for Applied Research (2015-16) of The University of Hong Kong. 


\section{References}

[1] Y. Liu, R.W. Weyers, Modeling the time-to-corrosion cracking in chloride contaminated reinforced concrete structures, ACI Materials Journal 95 (1998) 675-681.

[2] K. Bhargava, A.K. Ghosh, Y. Mori, S. Ramanujam, Model for cover cracking due to rebar corrosion in RC structures, Engineering Structures 28 (2006) 1093-1109.

[3] K.G. Papakonstantinou, M. Shinozuka, Probabilistic model for steel corrosion in reinforced concrete structures of large dimensions considering crack effects, Engineering Structures 57 (2013) 306-326.

[4] S.J. Han, D.H. Lee, K.S. Kim, S.Y. Seo, J. Moon, J.M. Monteiro Paulo, Degradation of flexural strength in reinforced concrete members caused by steel corrosion, Construction and Building Materials 54 (2014) 572-583.

[5] Z.P. Bažant, Physical model for steel corrosion in concrete sea structures -- application, Journal of the Structural Division, 105(6) (1979) 1155-1166.

[6] T. El Maaddawy, K. Soudki, A model for prediction of time from corrosion initiation to corrosion cracking, Cement \& Concrete Composites 29 (2007) 168-175.

[7] R. Tepfers, Cracking of concrete cover along anchored deformed reinforcing bar, Magazine of Concrete Research 31(106) (1979) 3-12.

[8] X.H. Wang, X.L. Liu, Modelling effects of corrosion on cover cracking and bond in reinforced concrete, Magazine of Concrete Research 56(4) (2004) 191-199.

[9] X.H. Wang, X.L. Liu, Modeling bond strength of corroded reinforcement without stirrups, Cement and Concrete Research 34 (2004) 1331-1339.

[10] K. Bhargava, A.K. Ghosh, Y. Mori, S. Ramanujam, Analytical model for time to cover cracking in RC structures due to rebar corrosion, Nuclear Engineering and Design 236 (2006) 1123-1139.

[11] K. Bhargava, A.K. Ghosh, Y. Mori, S. Ramanujam, Modeling of time to corrosioninduced cover cracking in reinforced concrete structures, Cement and Concrete Research 35 (2005) 2203-2218.

[12] K. Bhargava, A.K. Ghosh, Y. Mori, S. Ramanujam, Analytical model of corrosioninduced cracking of concrete considering the stiffness of reinforcement, Structural Engineering and Mechanics 16(6) (2003) 749-769.

[13] I. Balafas, C.J. Burgoyne, Modeling the structural effects of rust in concrete cover, Journal of Engineering Mechanics ASCE 137 (2011) 175-185. 
[14] C.Q. Li, R.E. Melchers, J.J. Zheng, Analytical model for corrosion-induced crack width in reinforced concrete structures, ACI Structural Journal 103(4) (2006) 479-487.

[15] C.Q. Li, S.T. Yang, Prediction of Concrete Crack Width under Combined Reinforcement Corrosion and Applied Load, Journal of Engineering Mechanics 137(11) (2011) 722-731.

[16] L. Chernin, D.V. Val, K.Y. Volokh, Analytical modelling of concrete cover cracking caused by corrosion of reinforcement, Materials and Structures 43(4) (2010) 543-556.

[17] K.H. Kim, S.Y. Jang, B.S. Jang, B.H. Oh. Modeling mechanical behavior of reinforced concrete due to corrosion of steel bar. ACI Materials Journal 107(2) (2010) 106-113.

[18] Y.X. Zhao, J. Yu, W.L Jin, Damage analysis and cracking model of reinforced concrete structures with rebar corrosion, Corrosion Science 53 (2011) 3388-3397.

[19] M.H. Shodja, K. Kiani, A. Hashemian, A model for the evolution of concrete deterioration due to reinforcement corrosion, Mathematical and Computer Modelling 52 (2010) 1403-1422.

[20] K. Kiani, M.H. Shodja, Prediction of the penetrated rust into the microcracks of concrete caused by reinforcement corrosion, Applied Mathematical Modelling 35 (2011) 2529-2543.

[21] S. Pantazopoulou, K. Papoulia, Modeling cover-cracking due to reinforcement corrosion in RC structures, Journal of Engineering Mechanics ASCE 127 (2001) 342-351.

[22] K. Toongoenthong, K. Maekawa, Simulation of coupled corrosive product formation, migration into crack and propagation in reinforced concrete sections. Journal of Advanced Concrete Technology 3(2) (2005) 253-265.

[23] Y.X. Zhao, W.L. Jin, Modeling the amount of steel corrosion at the cracking of concrete cover. Advances in Structural Engineering 9(5) (2006) 687-196.

[24] B. Šavija, M. Luković, J. Pacheco, E. Schlangen, Cracking of the concrete cover due to reinforcement corrosion: A two-dimensional lattice model study, Construction and Building Materials 44 (2013) 626-638.

[25] Y.X. Zhao, Y.Y. Wu, W.L. Jin, Distribution of millscale on corroded steel bars and penetration of steel corrosion products in concrete, Corrosion Science 66 (2013) 160-168.

[26] Y.X. Zhao, H.J. Ding, W.L. Jin, Development of the corrosion-filled paste and corrosion layer at the steel/concrete interface, Corrosion Science 87 (2014) 199-210.

[27] X.L. Du, L. Jin, R.B. Zhang, Modeling the cracking of cover concrete due to nonuniform corrosion of reinforcement, Corrosion Science, 89 (2014) 189-202. 
[28] C. Cao, Moe M.S. Cheung, Non-uniform rust expansion for chloride-induced pitting corrosion in RC structures, Construction and Building Materials, 51 (2014) 75-81.

[29] C. Cao, 3D simulation of localized steel corrosion in chloride contaminated reinforced concrete, Construction and Building Materials, 72 (2014) 434-443.

[30] S. Muthulingam, B.N. Rao, Non-uniform corrosion states of rebar in concrete under chloride environment, Corrosion Science 93 (2015) 267-282.

[31] E. Chen, Christopher K.Y. Leung, Finite element modeling of concrete cover cracking due to non-uniform steel corrosion, Engineering Fracture Mechanics, 134 (2015) 61-78.

[32] Y.X. Zhao, A.R. Karimi, H.S. Wong, B.Y. Hu, N.R. Buenfeld, W.L. Jin, Comparison of uniform and non-uniform corrosion induced damage in reinforced concrete based on a Gaussion description of the corrosion layer, Corrosion Science, 53 (2011) 2803-2814.

[33] A.C. Ugural, S.K. Fenster, Advanced Strength and Applied Elasticity, Elsevier Scientific Publishing Company, The Netherlands, 1977.

[34] Comité Euro-International du Béton-Fédération International de la Précontrainte, (CEB-FIP) Design Code, Thomas Telford, London, 1990.

[35] H.H. Chen, R.K.L. Su, Tension softening curves of plain concrete, Construction and Building Materials 44 (2013) 440-451.

[36] Z.P. Bažant, B. Oh, Crack-bond theory for fracture of concrete, Materials and Structures 16 (1983) 155-177.

[37] Y.X. Zhao, H.Y. Ren, H. Dai, W.L. Jin, Composition and expansion coefficient of rust based on X-ray diffraction and thermal analysis, Corrosion Science 53 (2011) 1646-1658.

[38] L. Chernin, D.V. Val, Prediction of corrosion-induced cover cracking in reinforced concrete structures. Construction and Building Materials 25 (2011) 1854-1869.

[39] H.S. Wong, Y.X. Zhao, A.R. Karimi, N.R. Buenfeld, W.L. Jin, On the penetration of corrosion products from reinforcing steel into concrete due to chloride-induced corrosion. Corrosion Science 52 (2010) 2469-2480.

[40] J. Ožbolt, F. Oršanić, G. Balabanić, M. Kušter, Modeling damage in concrete caused by corrosion of reinforcement: coupled 3D FE model, International Journal of Fracture 178 (2012) 233-244.

[41] Y.X. Zhao, J. Yu, Y.Y. Wu, W.L. Jin. Critical thickness of rust layer at inner and out surface cracking of concrete cover in reinforced concrete structures, Corrosion Science 59 (2012) 316-323. 
[42] S. Caré, Q.T. Nguyen, V. L'Hostis, Y. Berthaud, Mechanical properties of the rust layer induced by impressed current method in reinforced mortar, Cement and Concrete Research 38 (2008) 1079-1091.

[43] P. Hosemann, J.G. Swadener, J. Welch, N. Li, Nano-indentation measurement of oxide layers formed in LBE on F/M steels, Journal of Nuclear Materials 377(1) 2008 201-205.

[44] K. Lundgren, Modelling the effect of corrosion on bond in reinforced concrete, Magazine of Concrete Research 54 (3) (2002) 165-173.

[45] K. Lundgren, Modelling bond between corroded reinforcement and concrete. Fracture mechanics of concrete structures (2001) 247-254.

[46] A. Ouglova, Y. Berthaud, M. Franc, F. Foct, Mechanical properties of an iron oxide formed by corrosion in reinforced concrete structures, Corrosion Science 48 (2006) 3988-4000.

[47] Y.X. Zhao, H. Dai, H.Y. Ren, W.L. Jin, Experimental study of the modulus of steel corrosion in a concrete port, Corrosion Science 56 (2012) 17-25.

[48] Y.X. Zhao, H. Dai, W.L. Jin, A study of the elastic moduli of corrosion products using nano-indentation techniques, Corrosion Science 65 (2012) 163-168.

[49] K. Vu, M. G. Stewart, J. Mullard, Corrosion-induced cover cracking: experimental data and predictive models, ACI Structural 102 (5) (2005) 719-726.

[50] ACI Committee 318, Building code requirements for structural concrete (ACI 318M-02) and commentary (318RM-02), American Concrete Institute, Farmington Hills 2002.

[51] C. Alonso, C. Andrade, J. Rodriguez, J.M. Diez, Factors controlling cracking of concrete affected by reinforcement corrosion, Meterials and Structures, 31 (1998) 435441.

[52] T. Vidal, A. Castel, R. François, Analyzing crack width to predict corrosion in reinforced concrete, Cement and concrete Research, 34 (2004) 165-174.

[53] I. Balafas, C.J. Burgoyne, Environmental effects on cover cracking due to corrosion, Cement and Concrete 40 (2010) 1429-1440. 


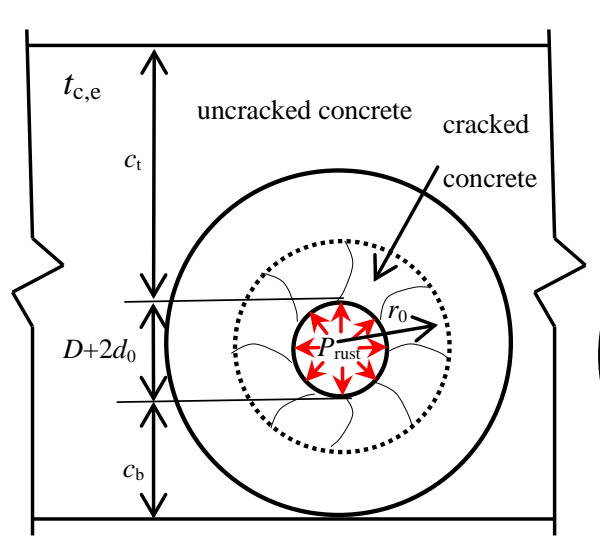

(a)

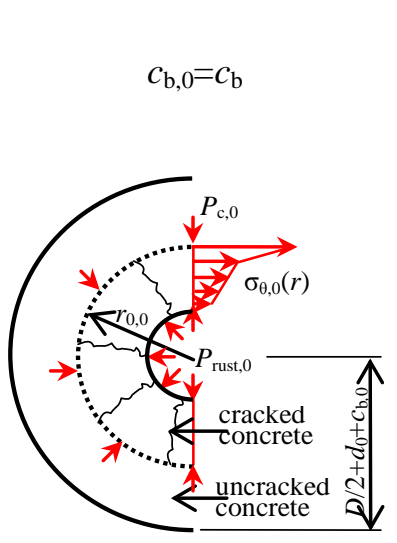

(b)

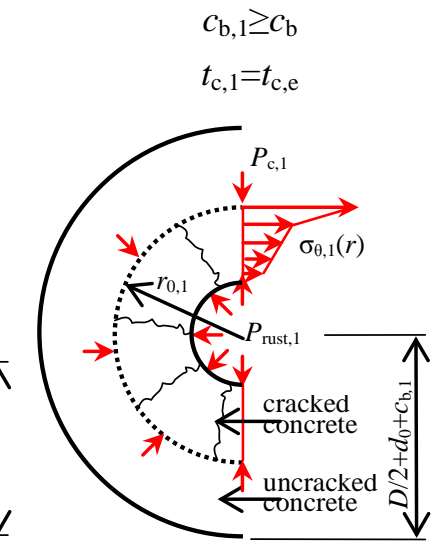

(c)

Fig. 1. The corrosion problem: (a) the actual case, (b) the traditional analytical model, and (c) the proposed analytical model

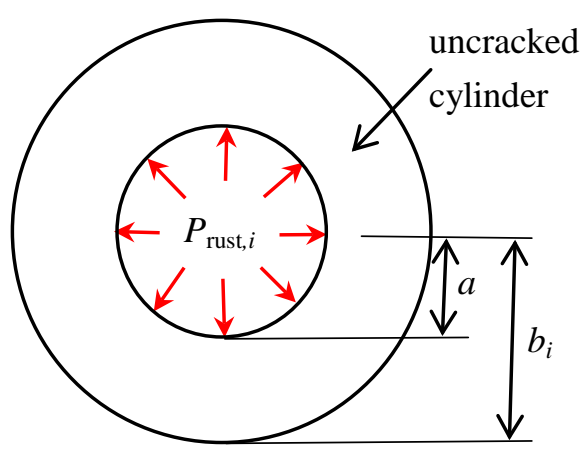

(a)

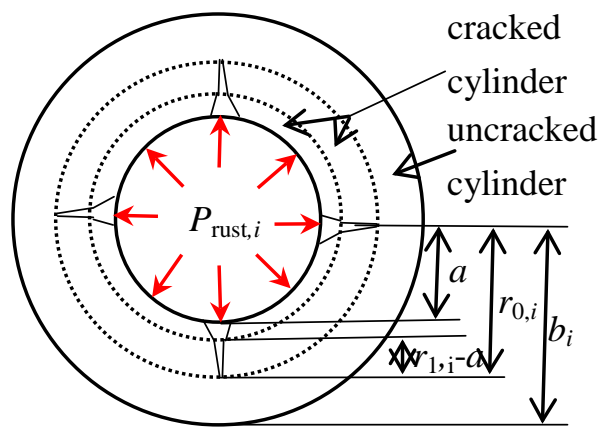

(c)

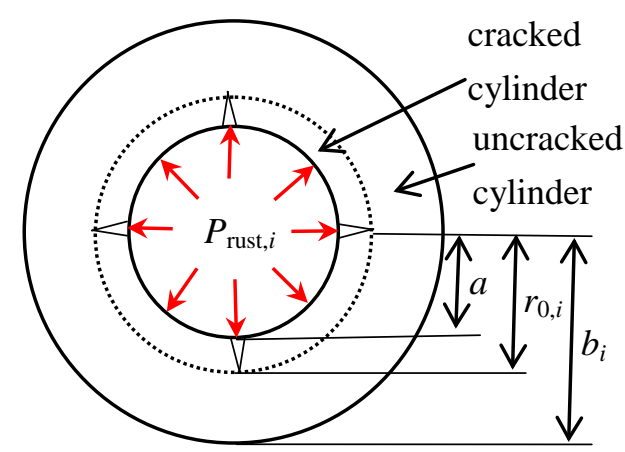

(b)

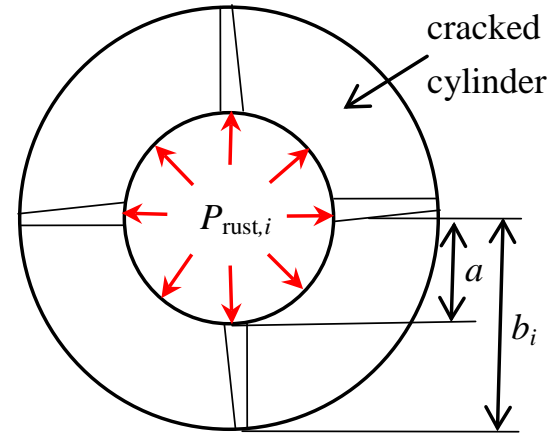

(d)

Fig. 2. Double-cylinder cracking model: (a) the stress initiation stage, (b) the first partial cracking stage, (c) the second partial cracking stage, and (d) the complete cracking stage 


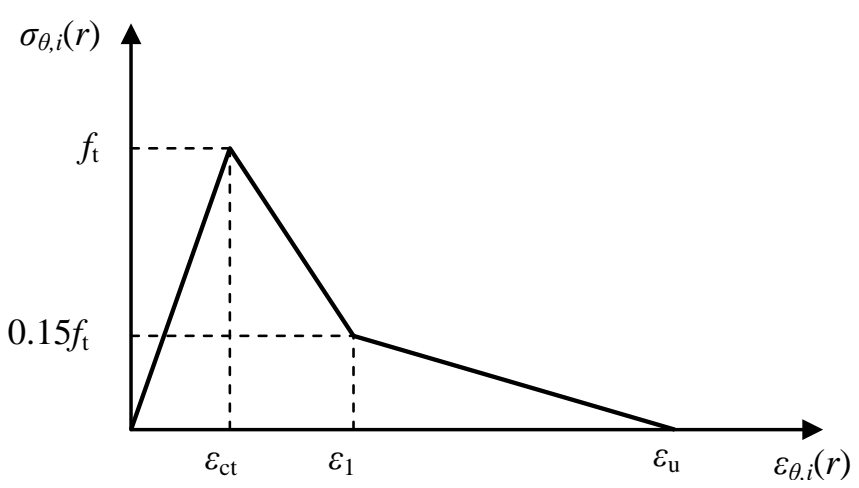

Fig. 3. Stress-strain relationship of concrete in tension

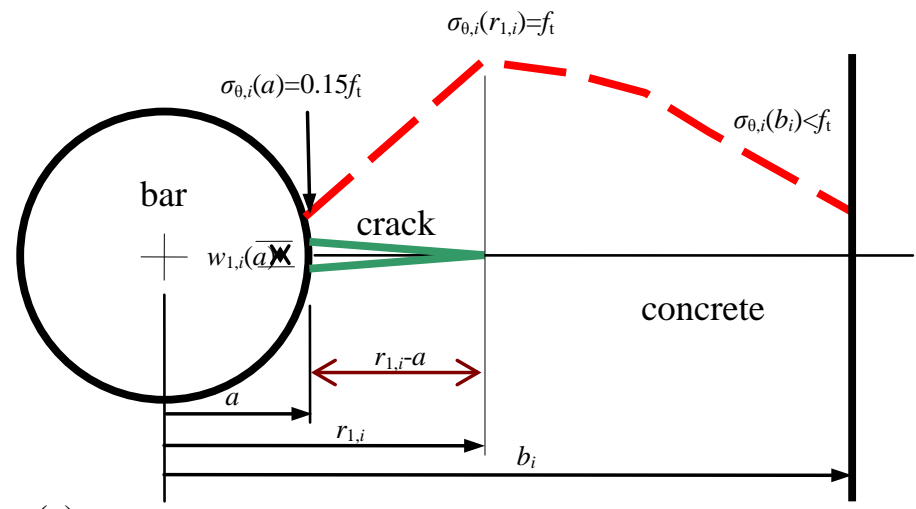

(a)

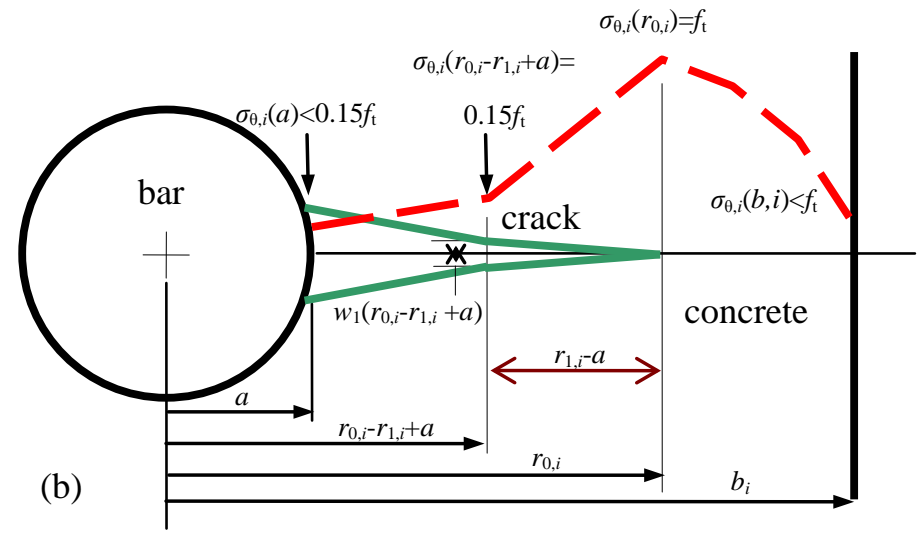

Fig. 4. Tensile stress distribution in cracked concrete: (a) the first partial cracking stage $\left(\sigma_{\theta, i}(a)=0.15 f_{t}\right)$, and (b) the second partial cracking stage 


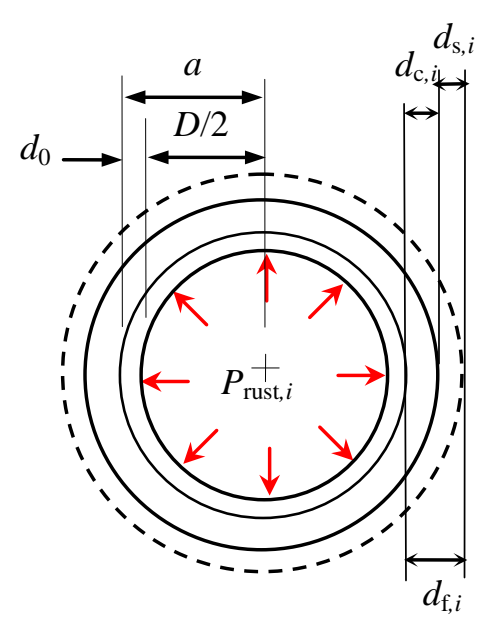

Fig. 5. Deformation compatibility

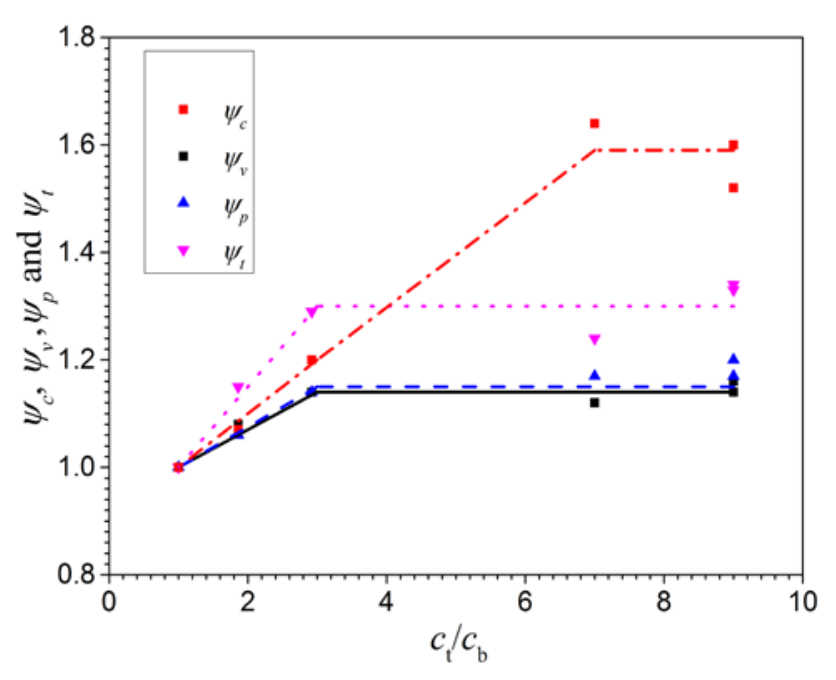

Fig. 6. Effects of $c_{\mathrm{t}} / c_{\mathrm{b}}$ on $\psi_{c}, \psi_{v}, \psi_{p}$ and $\psi_{t}$ 


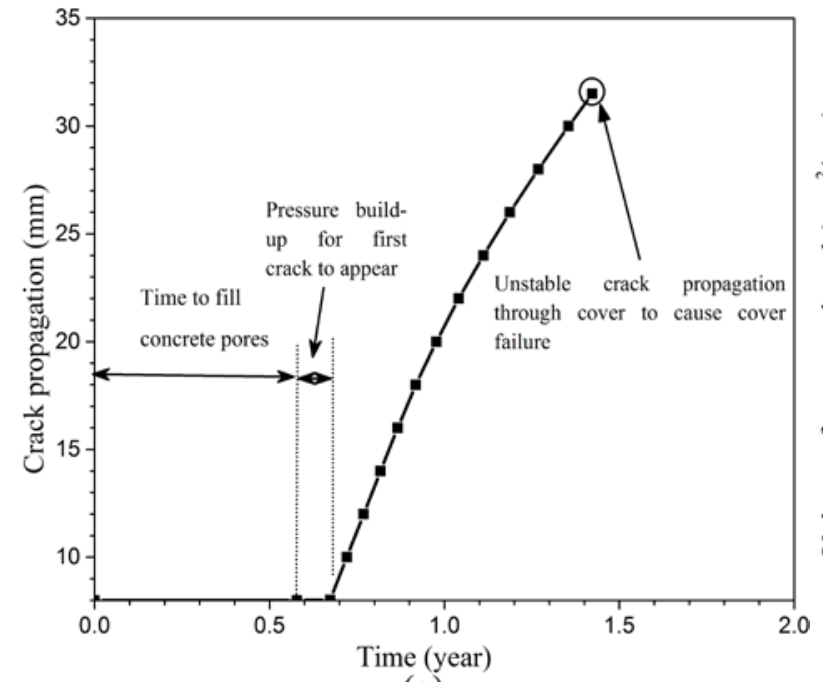

(a)

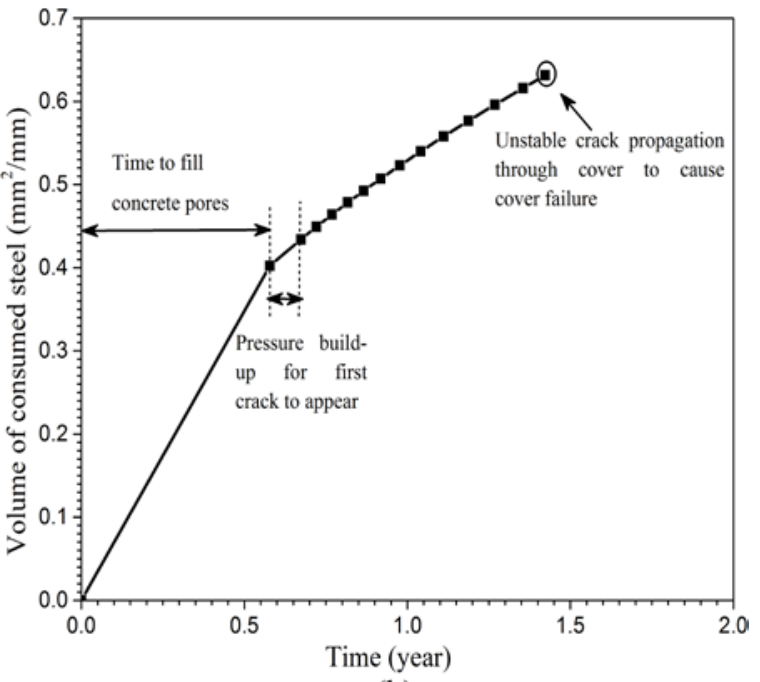

(b)

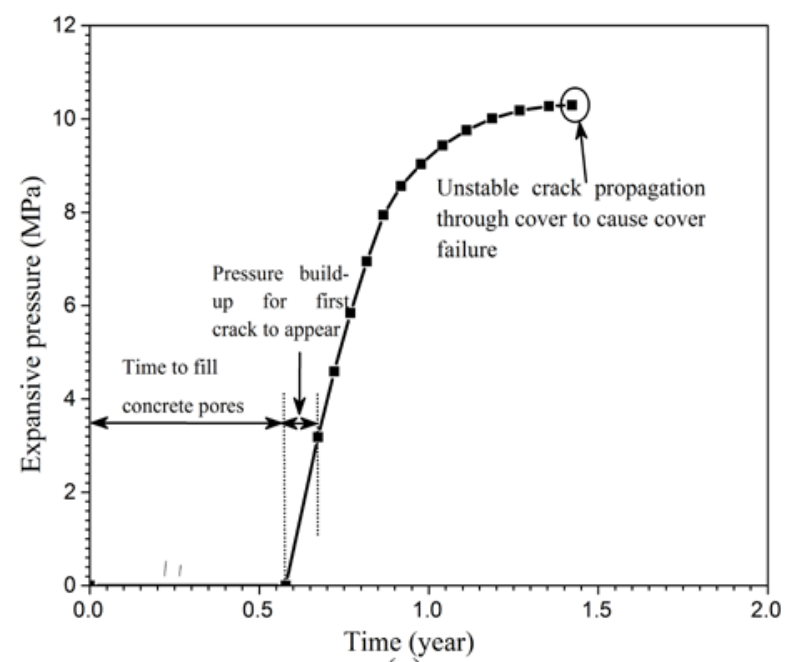

(c)

Fig. 7. Effects of time on: (a) smeared crack propagation, (b) volume of consumed steel, and (c) expansive pressure ( $D=16 \mathrm{~mm}, E_{\mathrm{r}}=80 \mathrm{GPa}, \beta=3, \lambda=0.45, d_{0}=16 \mu \mathrm{m}, f_{\mathrm{t}}=3.3 \mathrm{MPa}, c=51 \mathrm{~mm}$ ) 


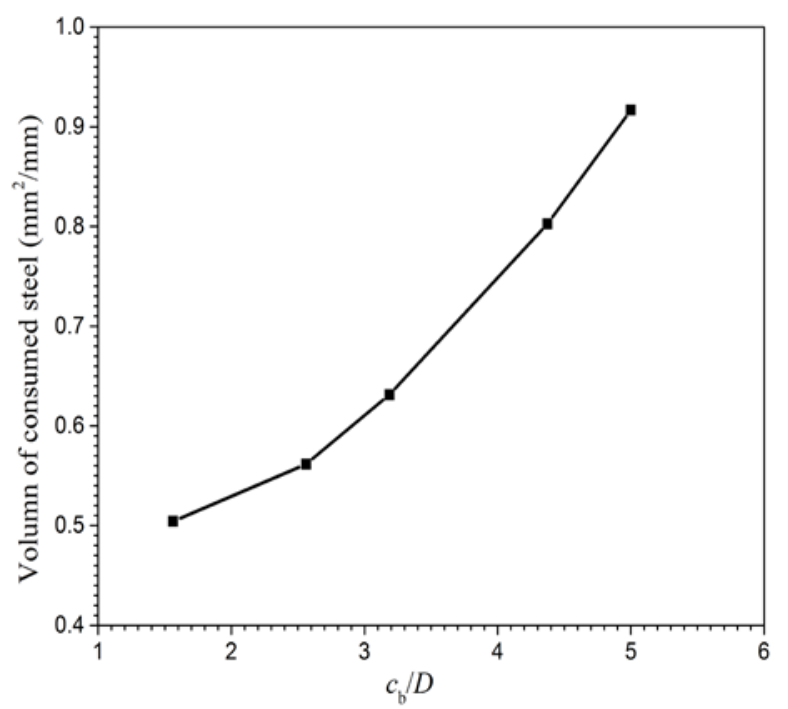

(a)

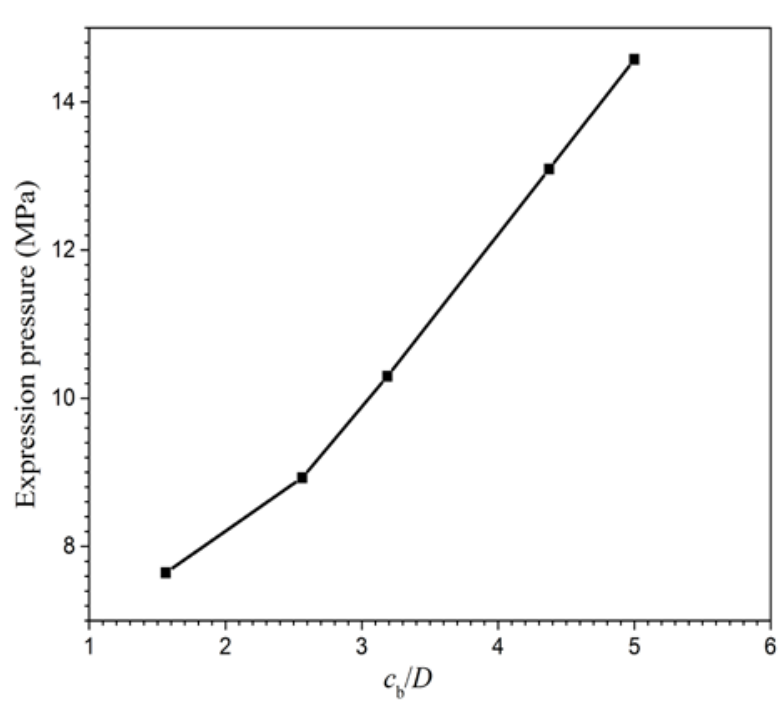

(b)

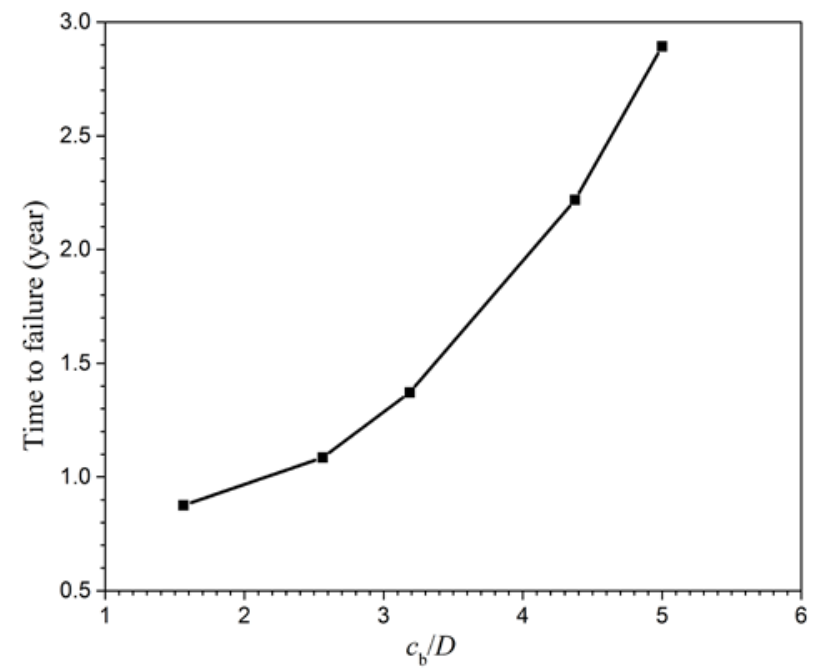

(c)

Fig. 8. Effects of the ratio of cover thickness to reinforcing bar diameter, $c_{\mathrm{b}} / D$, on: (a) critical volume of consumed steel, (b) critical expansive pressure, and (c) time to cover failure $\left(E_{\mathrm{r}}=80 \mathrm{GPa}, \beta=3, \lambda=0.45, d_{0}=16 \mu \mathrm{m}, \mathrm{f}_{\mathrm{t}}=3.3 \mathrm{MPa}\right)$ 


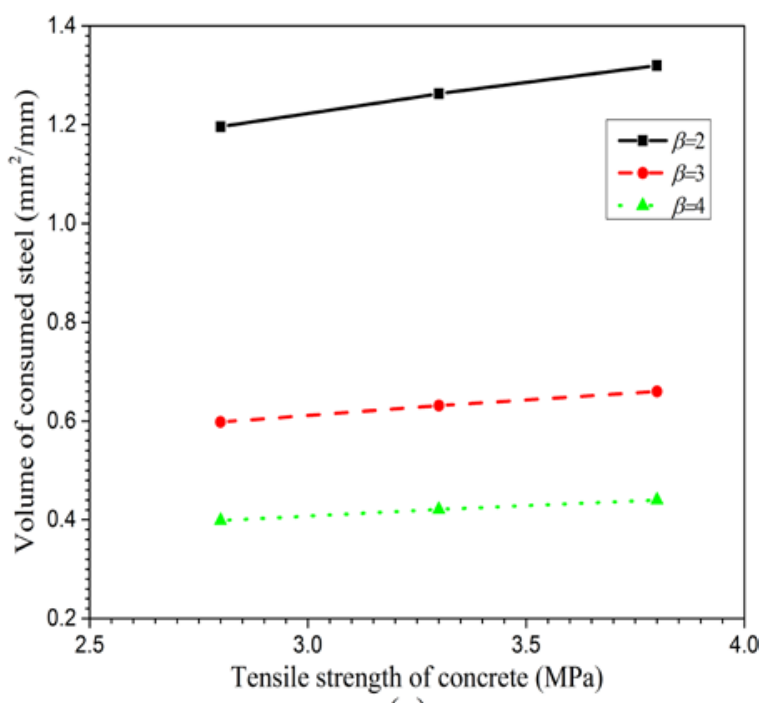

(a)

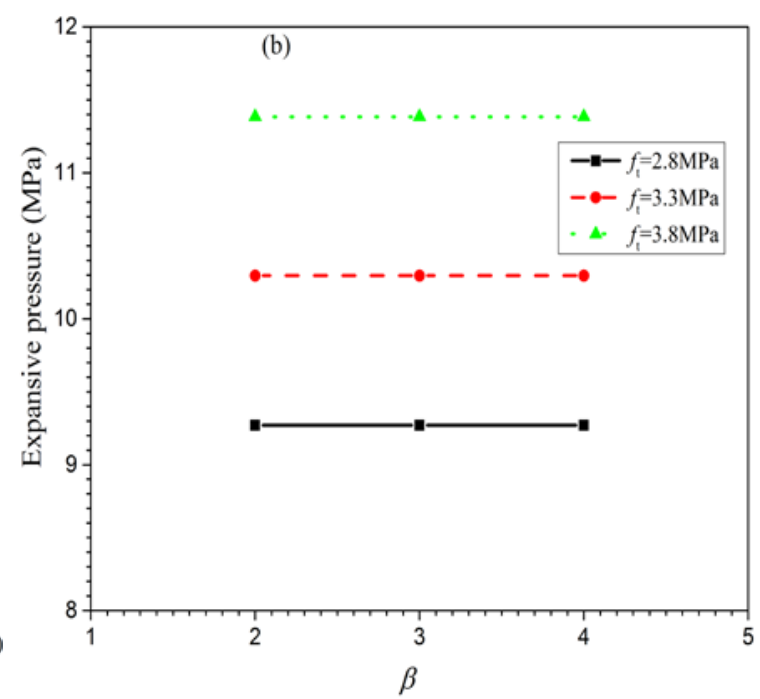

(b)

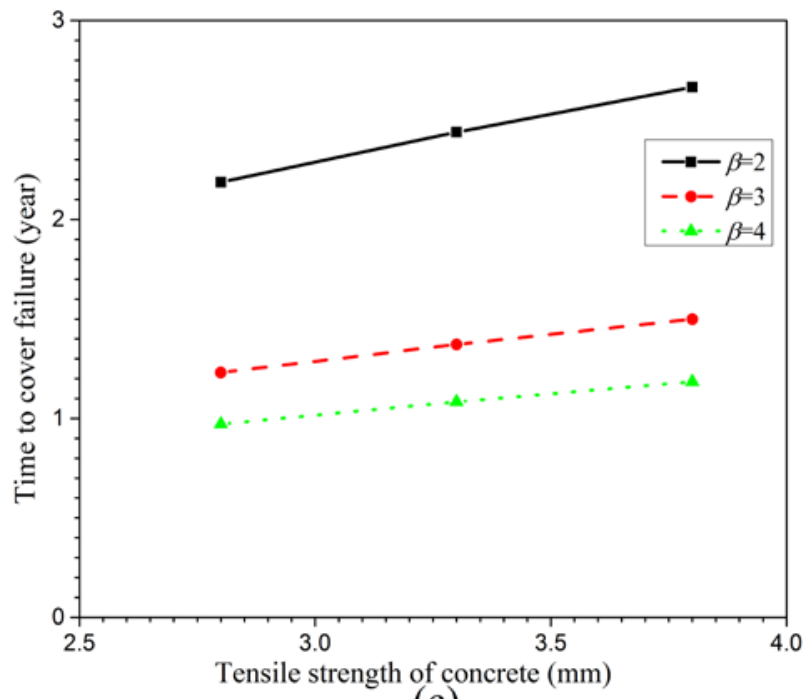

(c)

Fig. 9. Effects of tensile strength of concrete for different types of corrosion products on: (a) critical volume of consumed steel, (b) critical expansive pressure, and (c) time to cover failure $\left(D=16 \mathrm{~mm}, E_{\mathrm{r}}=80 \mathrm{GPa}, \lambda=0.45, d_{0}=16 \mu \mathrm{m}, c=51 \mathrm{~mm}\right)$ 


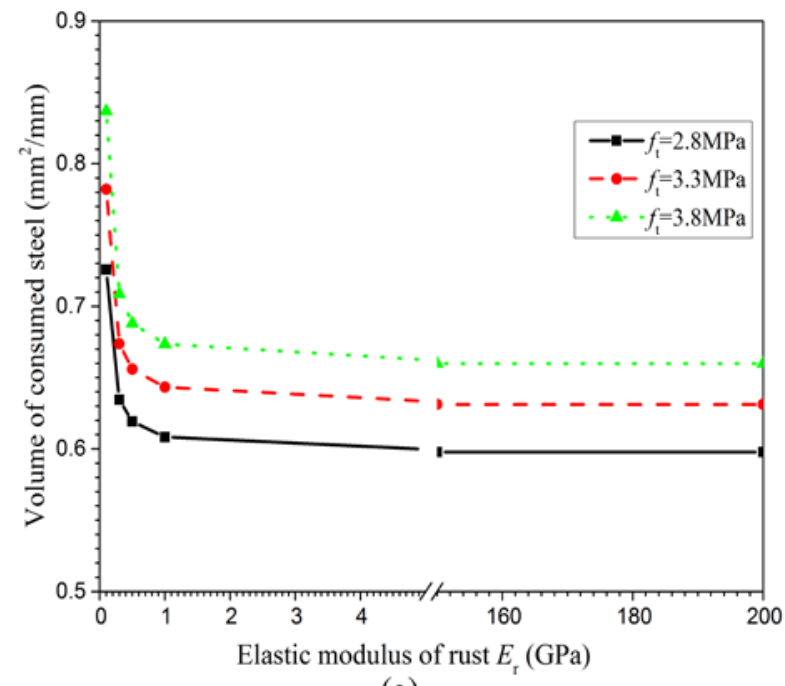

(a)

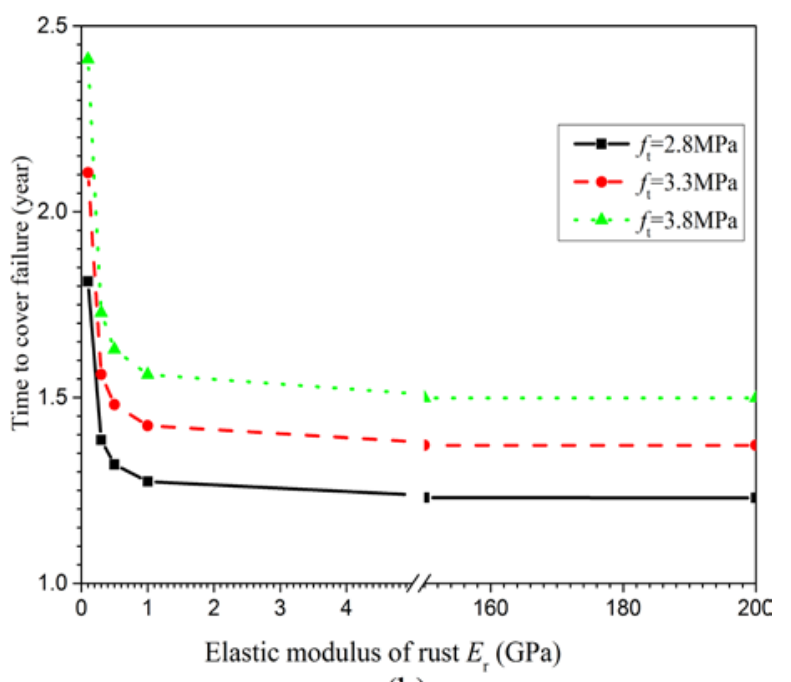

(b)

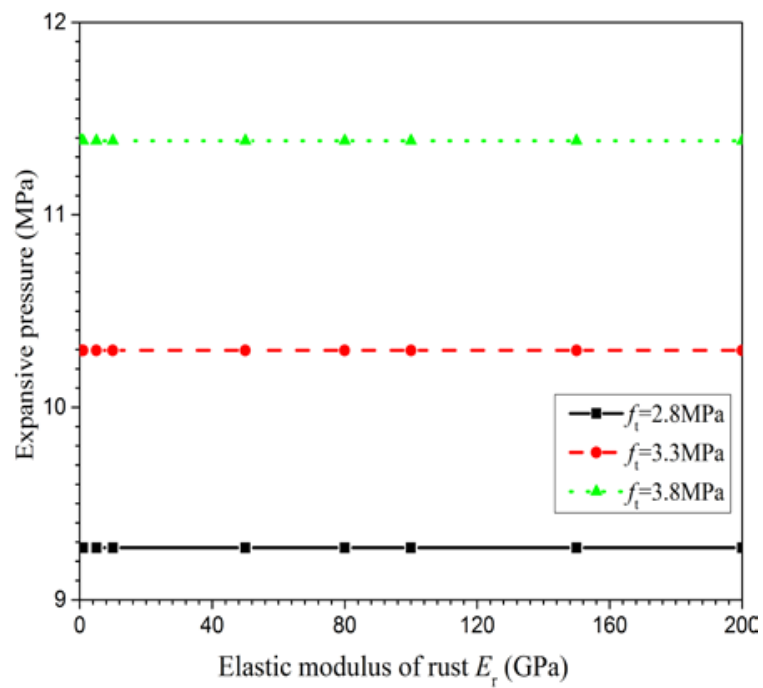

(c)

Fig. 10. Effects of elastic modulus of rust for different concrete tensile strengths on: (a) critical volume of consumed steel, (b) time to cover failure, and (c) critical expansive pressure ( $D=16 \mathrm{~mm}, \beta=3, \lambda=0.45, d_{0}=16 \mu \mathrm{m}, c=51 \mathrm{~mm}$ ) 


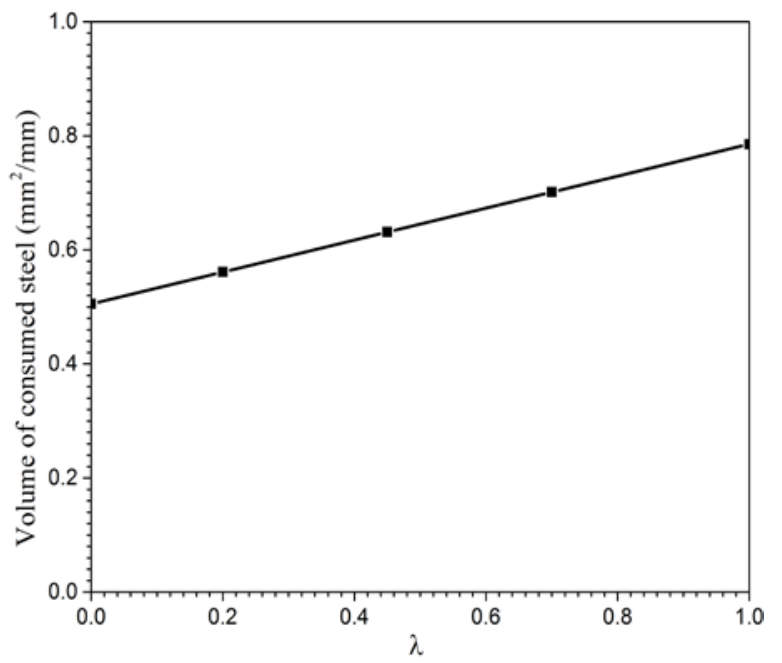

(a)

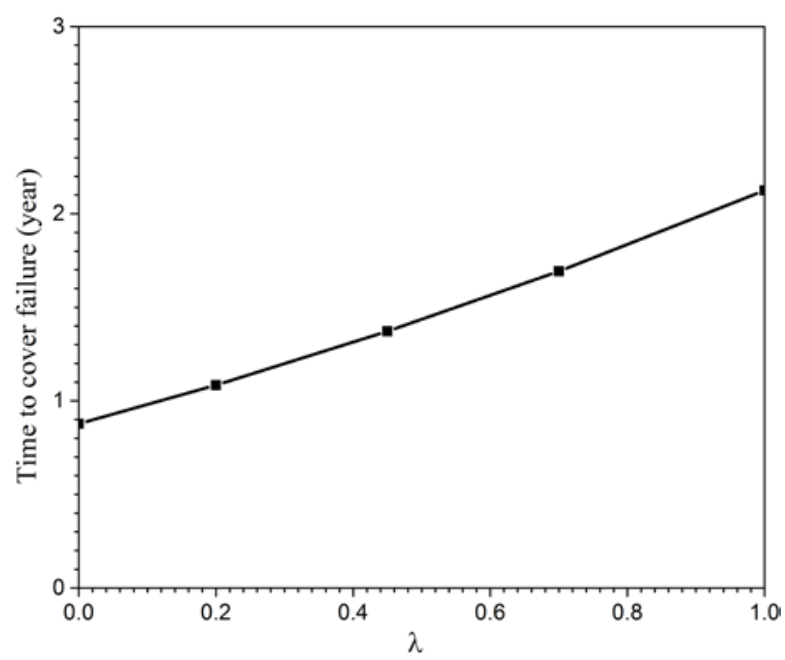

(b)

Fig. 11. Effects of $\lambda$ on: (a) critical volume of consumed steel, and (b) time to cracking $\left(D=16 \mathrm{~mm}, E_{\mathrm{r}}=80 \mathrm{GPa}, \beta=3, d_{0}=16 \mu \mathrm{m}, f_{\mathrm{t}}=3.3 \mathrm{MPa}, c=51 \mathrm{~mm}\right)$ 
Table 1

Basic experimental parameters.

\begin{tabular}{c|c|c|c|c|c|c|c|c|c}
\hline Unit & $\begin{array}{c}D \\
(\mathrm{~mm})\end{array}$ & $w / c$ & $\begin{array}{c}f_{\mathrm{c}} \\
(\mathrm{MPa})\end{array}$ & $\begin{array}{c}f_{\mathrm{t}} \\
(\mathrm{MPa})\end{array}$ & $\begin{array}{c}E_{\mathrm{c}} \\
(\mathrm{GPa})\end{array}$ & $\begin{array}{c}c_{\mathrm{b}} \\
(\mathrm{mm})\end{array}$ & $\begin{array}{c}c_{\mathrm{t}} \\
(\mathrm{mm})\end{array}$ & $\begin{array}{c}i_{\mathrm{cor}} \\
\left(\mu \mathrm{A} / \mathrm{cm}^{2}\right)\end{array}$ & $\begin{array}{c}t_{\mathrm{c}, \mathrm{e}} \\
(\text { year })\end{array}$ \\
\hline $\mathrm{A}[1]$ & 16 & 0.42 & 31.5 & 3.3 & 27 & 25 & 175 & 3.75 & 0.72 \\
$\mathrm{~B}[1]$ & 16 & 0.42 & 31.5 & 3.3 & 27 & 51 & 149 & 2.41 & 1.84 \\
$\mathrm{C}[1]$ & 16 & 0.42 & 31.5 & 3.3 & 27 & 70 & 130 & 1.79 & 3.54 \\
D [49] & 16 & 0.50 & 20 & 3.06 & $22^{*}$ & 25 & 225 & 140.3 & 0.0110 \\
E [49] & 16 & 0.58 & 42.3 & 3.76 & $30^{*}$ & 25 & 225 & 140.3 & 0.0111 \\
\hline
\end{tabular}

Note: $f_{\mathrm{c}}$ is the compressive strength of the concrete cylinder; $t_{\mathrm{c}, \mathrm{e}}$ is the time to cover cracking in the experiments; $w / C$ is the water to cement ratio; ${ }^{*}$ calculated value based on $E_{\mathrm{c}}=4600 \sqrt{ } f_{\mathrm{c}}$ recommended in ACI318-02[50].

Table 2

Predicted and test results.

\begin{tabular}{|c|c|c|c|c|c|}
\hline Unit & $c_{\mathrm{t}} / c_{\mathrm{b}}$ & $t_{\mathrm{c}, \mathrm{e}}($ year $)$ & $c_{b, 1}$ & $t_{\mathrm{c}, 1}$ (year) & $\left(t_{\mathrm{c}, 1} / t_{\mathrm{c}, \mathrm{e}}-1\right) \times 100(\%)$ \\
\hline $\mathrm{A}[1]$ & 7 & 0.72 & $\begin{array}{l}25 \\
35 \\
41 \\
45\end{array}$ & $\begin{array}{l}0.58 \\
0.63 \\
\mathbf{0 . 7 2} \\
0.79\end{array}$ & $\begin{array}{c}-20 \\
-13 \\
0 \\
10\end{array}$ \\
\hline $\mathrm{B}[1]$ & 2.92 & 1.84 & $\begin{array}{l}51 \\
61 \\
70 \\
80\end{array}$ & $\begin{array}{l}1.42 \\
1.83 \\
2.30 \\
3.00\end{array}$ & $\begin{array}{c}23 \\
\mathbf{1} \\
25 \\
63\end{array}$ \\
\hline $\mathrm{C}[1]$ & 1.86 & 3.54 & $\begin{array}{l}70 \\
75 \\
80 \\
85\end{array}$ & $\begin{array}{l}3.10 \\
3.55 \\
4.04 \\
4.60\end{array}$ & $\begin{array}{c}-22 \\
0 \\
14 \\
30\end{array}$ \\
\hline D [49] & 9 & 0.0110 & $\begin{array}{l}25 \\
35 \\
38 \\
45\end{array}$ & $\begin{array}{l}0.0083 \\
0.0102 \\
\mathbf{0 . 0 1 1 1} \\
0.0135\end{array}$ & $\begin{array}{c}-25 \\
-7 \\
1 \\
23\end{array}$ \\
\hline E [49] & 9 & 0.0111 & $\begin{array}{l}25 \\
35 \\
40 \\
45\end{array}$ & $\begin{array}{l}0.0086 \\
0.0099 \\
\mathbf{0 . 0 1 1 2} \\
0.0129\end{array}$ & $\begin{array}{c}-23 \\
-11 \\
1 \\
16\end{array}$ \\
\hline
\end{tabular}

Note: (1) $t_{\mathrm{c}, \mathrm{e}}$ and $t_{\mathrm{c}, 1}$ are, respectively, the measured and predicted time to cover cracking.

(2) Bolded figures correspond to the most accurate cover thickness. 
Table 3

Predicted results of $\psi_{c}, \psi_{v}, \psi_{p}$ and $\psi_{t}$.

\begin{tabular}{cccccc} 
Unit & $c_{2} / c_{1}$ & $\psi_{c}$ & $\psi_{v}$ & $\psi_{p}$ & $\psi_{t}$ \\
\hline $\mathrm{A}$ & 7.00 & 1.64 & 1.12 & 1.17 & 1.24 \\
$\mathrm{~B}$ & 2.92 & 1.20 & 1.14 & 1.14 & 1.29 \\
$\mathrm{C}$ & 1.86 & 1.07 & 1.08 & 1.06 & 1.15 \\
$\mathrm{D}$ & 9.00 & 1.52 & 1.16 & 1.20 & 1.34 \\
$\mathrm{E}$ & 9.00 & 1.60 & 1.14 & 1.17 & 1.33 \\
\hline
\end{tabular}

